\title{
Sulfur Dioxide Disproportionation For Sulfur Based Thermochemical Energy \\ Storage
}

\author{
Bunsen Wong ${ }^{1}$, Lloyd Brown ${ }^{1}$, Robert Buckingham ${ }^{1}$, Wendi Sweet ${ }^{1}$, B. Russ ${ }^{1}$ \\ and Max Gorensek ${ }^{2}$ \\ ${ }^{1}$ General Atomics, 3550 General Atomics Ct., San Diego CA 92121 USA; \\ ${ }^{2}$ Computational Sciences Directorate, Savannah River National Lab., Aiken, SC 29808, USA \\ "Contact: Email: bunsen.wong@ga.com; Phone: (858) 455-2611
}

\begin{abstract}
Sulfur dioxide disproportionation is one of three reaction steps that make up the sulfur based thermochemical cycle used for thermal energy storage of concentrated solar power. The characteristics of this reaction were studied using thermodynamic modeling and laboratory measurements. Modeling results showed full disproportionation can only be achieved at pressure. The reaction driving force is enhanced by system pressure but declines with increasing temperature. Appropriate water to sulfur dioxide ratio also drives disproportionation. Batch experiments showed that reaction rate increases with temperature. A catalyst survey identified homogenous iodides as catalysts that can improve the reaction rate by up to twenty times while increasing the apparent extent of disproportionation. The dependence of disproportionation rate on sulfuric acid concentration was established via constant pressure experiments. Means to recover the iodide catalyst from sulfuric acid and molten sulfur for reuse were demonstrated. Modeling and test results were used to establish a design concept for a sulfur dioxide disproportionation reactor system capable of rapidly generating sulfur as required for the sulfur based thermochemical energy storage technology.




\section{Introduction}

Concentrated solar power (CSP) integrated with thermal energy storage (TES) allows for the production of utility scale electricity during periods of intermittent or even extended absence of insolation. More importantly, TES collects solar energy and uses it to meet grid demand at all hours of the day. Its implementation increases power dispatchability and power block stability, increases CSP plant efficiency and capacity factor, and results in a lower levelized cost of electricity (LCOE) [1-3]. Current near-term TES employs molten salt (MS) as either sensible or latent heat storage medium. However, TES system performance is bounded by the physical properties of MS and cannot deliver the productivity a modern CSP plant is capable of. TES with higher energy storage capacity, higher output temperature and lower cost is needed. Integrating a sulfur based thermochemical cycle (Fig. 1) [4] into a CSP plant can provide the required high energy storage capacity, high available temperature and low cost. The cycle consists of three reaction steps:

$$
\begin{array}{lll}
\mathrm{H}_{2} \mathrm{SO}_{4} \text { Decomposition: } & 2 \mathrm{H}_{2} \mathrm{SO}_{4}(\mathrm{aq}) \rightarrow 2 \mathrm{H}_{2} \mathrm{O}(\mathrm{g})+\mathrm{O}_{2}(\mathrm{~g})+2 \mathrm{SO}_{2}(\mathrm{~g}) & 650-950^{\circ} \mathrm{C} \\
\mathrm{SO}_{2} \text { Disproportionation: } & 2 \mathrm{H}_{2} \mathrm{O}(\mathrm{l})+3 \mathrm{SO}_{2}(\mathrm{~g}) \rightarrow 2 \mathrm{H}_{2} \mathrm{SO}_{4}(\mathrm{aq})+\mathrm{S}(\mathrm{s}, \mathrm{l}) & 115-170^{\circ} \mathrm{C} \\
\mathrm{S} \mathrm{Combustion:} & \mathrm{S}(\mathrm{s}, \mathrm{l})+\mathrm{O}_{2}(\mathrm{~g}) \rightarrow \mathrm{SO}_{2}(\mathrm{~g}) & 500-1200^{\circ} \mathrm{C}
\end{array}
$$

First, sulfuric acid $\left(\mathrm{H}_{2} \mathrm{SO}_{4}\right)$ is decomposed into sulfur dioxide $\left(\mathrm{SO}_{2}\right)$ using high temperature solar heat. Next, $\mathrm{SO}_{2}$ is disproportionated with water into elemental sulfur and sulfuric acid. As a result, solar heat is stored in the chemical bonds of sulfur. In the third step, sulfur is burned in air to yield sulfur dioxide and release high temperature heat suitable for electricity generation. This TES technology produces no waste effluent and emits no greenhouse gas to the environment. Elemental sulfur and sulfuric acid are stored economically under ambient conditions. Since they can both be stored indefinitely, long-term TES is also possible. A comparison on CSP plant 
economics and operations between using sulfur and MS as TES medium is listed in Table 1. Storage capacity of sulfur is more than 20 times higher than MS while its material and storage costs are significantly lower. The technology is unique as heat can be recovered at a temperature $\left(1200^{\circ} \mathrm{C}\right)$ higher than that input $\left(500-900^{\circ} \mathrm{C}\right)$. Above all, the high output temperature enables the use of high efficiency power cycles. Sulfur based thermochemical storage has the potential to significantly improve CSP plant performance.

The three reaction steps are at different stages of technology development. Sulfur combustion is a commercial process used in sulfuric acid manufacturing. Power generation using combustion heat is being practiced in a number of plants. $\mathrm{H}_{2} \mathrm{SO}_{4}$ decomposition has been studied extensively since the 1970s as part of the effort to produce hydrogen via thermochemical water splitting [5-10]. It is the key reaction in both the sulfur-iodine (S-I) [11] and the hybrid sulfur cycles [12]. High temperature solar or nuclear heat is used to drive these thermochemical cycles. Successful short term on sun demonstration using process prototpyes have been carried out at $1-5 \mathrm{~kW}$ scale [13-15]. A $300 \mathrm{~kW}$ demonstration is currently in progress [16]. In contrast, $\mathrm{SO}_{2}$ disproportionation has only been studied in the laboratory [17,18]. Reaction thermodynamics and kinetics, especially at high $\mathrm{SO}_{2}$ concentrations, have not been investigated in detail prior to this work. In this paper, modeling and experimental measurements on the disproportionation characteristics of $\mathrm{SO}_{2}$ in water are presented. Effort to identify a suitable catalyst and its effects will be discussed. Finally, a preliminary design concept of a disproportionation reactor system based on experimental data will be proposed. 


\section{Thermodynamic Modeling of $\mathrm{SO}_{2}$ Disproportionation}

Thermodynamics of the $\mathrm{SO}_{2}$ disproportionation system are complex because of the non-ideal nature of the solution formed between sulfuric acid and water. Furthermore, $\mathrm{SO}_{2}$ can exist as a second liquid phase under pressure and it can also interact with sulfuric acid to form aqueous ionic complexes. To better understand the driving force(s) behind $\mathrm{SO}_{2}$ disproportionation, a thermodynamic model was developed using AspenPlus ${ }^{\circledR}$. The Electrolyte-NRTL activity coefficient model (ELECNRTL) and the latest sulfuric acid model provided by Aspen Tech were used to construct a system for thermodynamic studies. To characterize the interactions between $\mathrm{SO}_{2} / \mathrm{H}_{2} \mathrm{SO}_{4} / \mathrm{H}_{2} \mathrm{O}$, thermodynamic data from the OLI Inc. database was incorporated. The data's accuracy was validated in the $\mathrm{SO}_{2} / \mathrm{H}_{2} \mathrm{SO}_{4}$ system analysis conducted on the hybrid sulfur hydrogen cycle [19].

A Gibbs energy equilibrium model was used to predict the extent of disproportionation and $\mathrm{H}_{2} \mathrm{SO}_{4}$ concentration as a function of temperature, pressure and $\mathrm{H}_{2} \mathrm{O}: \mathrm{SO}_{2}$ ratio in the feed to the Gibbs reactor. The equilibrium constant, $K_{e q}$, for (2) is expressed as:

$$
K_{e q}=\frac{A_{H 2 S O 4}^{2} \bullet 1}{P_{S O 2}^{3} \bullet A_{H 2 O}^{2}}=\exp \left(-\frac{\Delta G_{D R_{0}}}{R T}\right)
$$

Figure 2(a) shows the equilibrium conversion of $\mathrm{SO}_{2}$ to sulfur at various temperatures and pressures. There exists a threshold pressure below which no disproportionation takes place. This threshold increases with temperature indicating that the driving force for disproportionation is inversely proportional to temperature. Elevated pressures are required to drive disproportionation to completion ( 0.33 mole of sulfur for each mole of $\mathrm{SO}_{2}$ ) at all temperatures. Hence, disproportionation at ambient pressure will be extremely sluggish, which agrees with experimental findings. The effect of water on disproportionation is more complicated. Based on the equilibrium expression (4), a higher water fraction will enhance its activity and reduce 
sulfuric acid activity at equilibrium. This drives disproportionation and lowers the threshold pressure. However, this trend only holds for intermediate $\mathrm{H}_{2} \mathrm{O}: \mathrm{SO}_{2}$ ratios [Fig. 2(b)]. For low ratios, there is inadequate water in the system resulting in high $\mathrm{H}_{2} \mathrm{SO}_{4}$ activity which impedes disproportionation. In other words, there is an upper bound on $\mathrm{H}_{2} \mathrm{SO}_{4}$ concentration in the $\mathrm{SO}_{2}$ disproportionation reaction. At high ratios, the driving force for disproportionation begins to decrease due to declining $\mathrm{SO}_{2}$ partial pressure. This is because $\mathrm{SO}_{2}$ is partially water soluble; a large amount of water acts to reduce the $\mathrm{SO}_{2}$ partial pressure and its disproportionation. Therefore, it is essential to regulate the $\mathrm{H}_{2} \mathrm{O}: \mathrm{SO}_{2}$ ratio to maximize both the disproportionation driving force and the acid concentration. This will reduce the load required for post disproportionation acid concentration in the overall processing scheme.

Since acid concentration is an important process variable due to its overall impact on system efficiency, the role of processing conditions on this parameter was examined. Figure 3(a) shows the effects of temperature and $\mathrm{H}_{2} \mathrm{O}: \mathrm{SO}_{2}$ ratio. Corresponding data points from single batch experiments (with iodide catalyst) are also plotted. A peak in acid concentration was found with respect to $\mathrm{H}_{2} \mathrm{O}: \mathrm{SO}_{2}$ ratio at all temperatures. To the right of the peak, higher water fraction dilutes the acid. On the other side, greater $\mathrm{H}_{2} \mathrm{SO}_{4}$ activity retards disproportionation and triggers a declining concentration. Higher acid concentrations are expected at low temperatures. Experimental data agrees well with the modeling results. The yield of sulfur is almost linear with respect to $\mathrm{H}_{2} \mathrm{O}: \mathrm{SO}_{2}$ ratio at low ratios [Fig. 3(b)]. It then becomes stoichiometric at high ratios. Interestingly, the theoretical maximum acid concentration is obtained at a $\mathrm{H}_{2} \mathrm{O}: \mathrm{SO}_{2}$ ratio slightly lower than that required to achieve full disproportionation. The optimum processing scheme will have to be assessed with a process flowsheet to balance the energy output required to evaporate excess water versus the energy gain with additional sulfur. 
Figure 3(c) shows that the maximum $\mathrm{H}_{2} \mathrm{SO}_{4}$ concentration will occur at the lowest system temperature for all pressures. System pressures beyond 30bar do not lead to much further increase in disproportionation. The measured final acid concentrations from single batch experiments are below those predicted by the model. The discrepancy can be attributed to the fact that the modeling results assume a constant system pressure throughout whereas the actual pressure decreases as the reaction proceeds. Disproportionation slows down significantly at low pressures when most of the $\mathrm{SO}_{2}$ has been reacted. Results showed that the AspenPlus ${ }^{\circledR}$ model developed for the $\mathrm{SO}_{2} / \mathrm{H}_{2} \mathrm{O} / \mathrm{S} / \mathrm{H}_{2} \mathrm{SO}_{4}$ system provides a good representation of the system thermodynamics and is used in process and system flowsheet designs for this study.

\section{Experimental Studies of $\mathrm{SO}_{2}$ Disproportionation}

$\mathrm{SO}_{2}$ disproportionation studies were carried out in both batch and constant pressure modes. Effects of temperature and catalyst on reaction kinetics were investigated in batch mode. Constant pressure experiments were used to simulate operations of an actual reaction system and determine the effect of acid concentration on kinetics. Experimental parameters were based on the highest sulfur yielding conditions as suggested by the modeling results. The resulting data were used to design a reactor system applicable to 24-hour operation of a baseload CSP plant.

\subsection{Experimental Details}

Candidate catalysts were mixed or dissolved in de-ionized water inside a $100 \mathrm{ml}$ Pyrex test cell [Fig. 4(a)]. Cell pressure equalization and $\mathrm{SO}_{2}$ feed was achieved via a $1 \mathrm{~mm}$ ID glass tube. After the cell was loaded with water and catalyst, it was placed inside a 1 L 316 stainless pressure vessel (Parr Model 4521, [Fig 4(b)]). The vessel's head and body were coated with tantalum by Tantaline ${ }^{\circledR}$. This helps to prevent vessel corrosions that could potentially affect the measurement results. The pressure inside the vessel was monitored by a pressure transducer 
(Reotemp TH1P31) mounted on the vessel head. The set up was then pressurized with helium to ensure that there was no leak. To fill the vessel with $\mathrm{SO}_{2}$, the vessel was placed in an acetone dry ice bath and cooled down to $-40^{\circ} \mathrm{C}$. Helium was vented once the setup was cooled. The vessel was then pumped down to 30 Torr to remove any remaining air and helium. Next, the evacuated vessel was connected to a feed tank so $\mathrm{SO}_{2}$ gas could condense inside the vessel. The amount of $\mathrm{SO}_{2}$ added was gauged by monitoring the feed tank weight so that a preset $\mathrm{SO}_{2}: \mathrm{H}_{2} \mathrm{O}$ ratio could be obtained. After $\mathrm{SO}_{2}$ addition, the vessel was sealed and allowed to warm up to room temperature. It was then placed in a furnace assembly and heated to test temperature. System pressure is determined largely by the test temperature and the amount of $\mathrm{SO}_{2}$ inside the vessel. It declines as $\mathrm{SO}_{2}$ disproportionates into sulfur and $\mathrm{H}_{2} \mathrm{SO}_{4}$ and the rate of pressure reduction indirectly reflects the disproportionation rate.

For constant pressure experiments, a $\mathrm{SO}_{2}$ syringe pump (Teledyne Isco 500D) was connected to the $\mathrm{SO}_{2}$ filled vessel [Fig 5(a)]. The connecting lines were evacuated to remove any dead gas volume. A control loop was used to maintain the system pressure at the test target during experiments. Once it dropped below the target by 25 psi, the pump would activate and slowly add liquid $\mathrm{SO}_{2}$ to raise the system pressure back to the target value. The instantaneous acid concentration can be calculated through the amount of $\mathrm{SO}_{2}$ consumed. the disproportionation rate as a function of acid concentration can thus be determined. Figure 5(b) shows the pressure profiles for both batch and constant pressure experiments. In batch mode, pressure declines steadily as $\mathrm{SO}_{2}$ disproportionates whereas it is maintained via repeated $\mathrm{SO}_{2}$ additions in the constant pressure mode. In both cases, the reaction is considered complete when the pressure change drops below $5 \mathrm{psi} / \mathrm{hr}$. The average reaction rate is calculated based on the time required at temperature for the reaction to finish. 
The resulting acid concentration was determined using titration with $\mathrm{NaOH}$ (Mettler Toledo T50) and density measurement. Qualitative iodine, iodide and various sulfur species contents in the acid solution were assessed using Raman Spectroscopy (Thermo Scientific DXR Raman Microscope with a $532 \mathrm{~nm}$ laser) [20-22]. Quantitative iodine species content in the acid solution was obtained using ICP-OES (Thermo Electron iCAP 6300). Sulfur produced from experiments was rinsed with de-ionized water followed by drying in air. Iodine content within the sulfur was determined by dissolving the solid in toluene and then analyzing the solvent solution with UVvis (Agilent Cary 50) [23]. Mass balance calculations using measured acid concentrations and the sulfur weight were carried out to define the extent of disproportionation and the reaction rate.

\subsection{Batch $\mathrm{SO}_{2}$ Disproportionation Experiments}

$\mathrm{SO}_{2}$ disproportionation in water is very slow even at elevated temperatures and pressures. Figure 6(a) shows it takes 250 hours or more for the reaction to complete. This is not practical for any engineering process and a catalyst is needed to increase the reaction to a more practical speed.

\section{2a Preliminary Catalyst Screening}

To maximize the reaction rate, a catalyst survey was carried out. A number of common heterogeneous and homogeneous catalysts were screened for their effectiveness to promote $\mathrm{SO}_{2}$ disproportionation. Screening test results showed that soluble iodide salts, i.e. KI and NaI, are considerably more effective than any other catalysts in speeding up $\mathrm{SO}_{2}$ disproportionation with water [Fig. 6(b)]. Figure 6(a) shows that an addition of 0.16 mole\% iodide salt in the starting water bath can increase the reaction rate by almost 15 times. The final acid concentration ranges between 57 to $62 \mathrm{wt} \%$ when an iodide catalyst is used compared to $42 \mathrm{wt} \%$ when absent. In conclusion, iodide salts are very effective catalysts to promote $\mathrm{SO}_{2}$ disproportionation. 


\section{2b Experiments with Iodide Catalysts}

A number of iodide salts were evaluated as catalysts as well as hydriodic acid (HI), which was produced by reducing elemental iodine in water with $\mathrm{SO}_{2}$ according to the Bunsen reaction:

$$
\mathrm{SO}_{2}(\mathrm{~g})+2 \mathrm{H}_{2} \mathrm{O}(\mathrm{l})+\mathrm{I}_{2}(\mathrm{~s}) \Leftrightarrow 2 \mathrm{HI}(\mathrm{aq})+\mathrm{H}_{2} \mathrm{SO}_{4}(\mathrm{aq})
$$

Figure 7(a) compares the effectiveness of various readily available iodides at temperatures between 90 and $140^{\circ} \mathrm{C}$. No difference in efficacy is observed between them, which verifies that iodide $\left(I^{-}\right)$is the essential catalytic chemical species. When selecting the most appropriate catalyst, one needs to consider its recovery for re-use. For $\mathrm{KI}, \mathrm{NaI}$ and $\mathrm{NH}_{4} \mathrm{I}$, it will involve either alkali salt precipitation or ammonia gas capture. This additional process step can be avoided if $\mathrm{HI}$ is used instead. Using $\mathrm{HI}$ as a catalyst, the disproportionate rates between 120 and $170^{\circ} \mathrm{C}$ at various catalyst loadings were investigated. Iodide fractions between 0.085 and 0.708 mole\% with respect to water were used [Figure 7(b)]. The measured reaction rates scale with catalyst loading and has an Arrhenius dependence on temperature. An Arrhenius expression describing the overall effect of temperature and catalyst on $\mathrm{SO}_{2}$ disproportionation was obtained based on least square fit of the experimental data:

$$
k=2.13 * 10^{7} *\left(\frac{I}{H 2 O}\right)^{0.75} * e^{-\left(\frac{7515}{T}\right)} / \mathrm{hr}
$$

Results show $\mathrm{SO}_{2}$ disproportionation can be completed in less than three hours with a high catalyst loading and a reaction temperature of $165^{\circ} \mathrm{C}$. This temperature represents the upper limit for a practical continuous reactor system because sulfur's viscosity increases dramatically above it [24], making extraction and pumping of sulfur from the reactor very difficult. With a faster reaction, a smaller reactor can be used but more catalyst must be recovered.

Mass balance calculations confirmed the experimental results to be self-consistent. Fig. 7c shows a plot between the measured sulfur weights and that calculated based on final acid 
concentrations. The measured values are slightly higher in some cases, probably due to elemental iodine trapped within the sulfur. This good agreement also indicates that side reactions that can form other sulfur species such as $\mathrm{H}_{2} \mathrm{~S}$ are largely absent.

\subsection{Constant Pressure $\mathrm{SO}_{2}$ Disproportionation Experiments}

In addition to catalyst and temperature, $\mathrm{SO}_{2}$ partial pressure and $\mathrm{H}_{2} \mathrm{SO}_{4}$ concentration also play a role in defining the disproportionation rate. Constant pressure experiments were carried out to determine their effects. Figure 8(a) shows the calculated $\mathrm{H}_{2} \mathrm{SO}_{4}$ concentration (based on $\mathrm{SO}_{2}$ consumption) as a function of reaction time from one run. A constant system pressure of $610 \mathrm{psig}$ at $150^{\circ} \mathrm{C}$ and catalyst loading of 0.17 mole\% were used. Accelerated reaction is observed between acid concentrations of 25 and 45 wt $\%$. Fast reactions in this concentration range were observed at all pressures. Figure $8(b)$ shows the least square regression fit of all data points from constant pressure experiments. An almost Gaussian distribution in the reaction rate is obtained with a maximum at $33 \mathrm{wt} \%$.

To explore the reason behind the acceleration, the acid chemical composition was examined at various stages of disproportionation. Raman spectroscopy was used in order to minimize disturbance to chemical equilibrium. Figure 9 shows the spectra at $t=0,4.4$ (fast reaction regime) and 10 (completion) hours respectively. At the onset, only a small dissolved $\mathrm{SO}_{2}$ peak is present (Raman cannot resolve $\mathrm{I}^{-}$). As disproportionation proceeds, sulfuric acid peaks become dominant. Most importantly, $\mathrm{I}_{3}{ }^{-}$peaks are present in the acid during the fast reaction regime. $\mathrm{I}_{3}{ }^{-}$ is a complex of $\mathrm{I}^{-}$and $\mathrm{I}_{2}$ and is most likely the catalytic species responsible for the accelerated reaction [25]:

$$
\begin{aligned}
& \mathrm{SO}_{2}(\mathrm{aq})+6 \mathrm{I}^{-}(\mathrm{aq})+4 \mathrm{H}^{+}(\mathrm{aq}) \rightarrow \mathrm{S}(\mathrm{s})+2 \mathrm{I}_{3}^{-}(\mathrm{aq})+2 \mathrm{H}_{2} \mathrm{O}(\mathrm{l}) \\
& \mathrm{I}_{3}^{-}(\mathrm{aq})+2 \mathrm{H}_{2} \mathrm{O}(\mathrm{l})+\mathrm{SO}_{2}(\mathrm{aq}) \rightarrow 4 \mathrm{H}^{+}(\mathrm{aq})+\mathrm{SO}_{4}{ }^{2-}(\mathrm{aq})+3 \mathrm{I}^{-}(\mathrm{aq})
\end{aligned}
$$


$\mathrm{I}_{3}{ }^{-}$forms when sulfuric acid concentration increases to the extent that it shifts the Bunsen reaction equilibrium, oxidizing some of iodide anions into elemental iodine. There exists a complex but complimentary equilibrium between the $\mathrm{SO}_{2}$ disproportionation and the Bunsen reactions.

The effect of constant system pressure on the final acid concentration is shown in Fig. 10(a). Increasing pressure drives the extent of disproportionation. However, the effect levels off as the pressure reaches above 500 psig ( $33 \mathrm{bar}$ ). These results agree well with the findings put forth by the Aspen model validating its functionality. Even though a high system pressure helps to increase disproportionation, it does not have a significant impact on reaction kinetics. It takes a similar amount of time to get to completion for all the pressures studied. Thus, a pressure of 600psig will be adequate.

\subsection{Kinetics Equation for $\mathrm{SO}_{2}$ Disproportionation}

Using the data from the constant pressure experiments together with the effect of iodine and temperature from the batch experiments, a rate expression was deduced for use in process flowsheet design. The data from seven constant pressure experiments at $150^{\circ} \mathrm{C}$ were used to determine the relationship of the net reaction rate to the chemical environment. A nonlinear least square analysis fit to the totality of the experimental data for each experiment. The Resultant rate expression is dominated by two observations: the rate increases with pressure (or $\mathrm{SO}_{2}$ partial pressure) and the rate increases with sulfuric acid concentration and then decreases with further increase in sulfuric acid concentration. The decrease in rate with sulfuric acid is readily explained as sulfuric acid is a product of the decomposition and increases the rate of the reverse reaction. The increase in rate with acid concentration is more complicated. If, as we assume, the 
catalytic species is $I_{3}^{-}$, formation of the catalytic species requires the formation of $\mathrm{HI}$ via the Bunsen reaction, which also form sulfuric acid.

Consider fitting the constant pressure experimental data was with an equation of the form:

$$
r=k * f\left(\mathrm{SO}_{2}\right) * f\left(\mathrm{H}_{2} \mathrm{O}, \mathrm{H}_{2} \mathrm{SO}_{4}\right) * f\left(\mathrm{I}_{3}^{-}\right)
$$

The formation of the catalyst $I_{3}^{-}$, is quite involved. Formation of $I_{3}^{-}$is convoluted with the activities of water and sulfuric acid according to the Bunsen Reaction (5) and the HI- $\mathrm{I}_{2}$ equilibrium:

$$
\mathrm{HI}(\mathrm{aq})+\mathrm{I}_{2}(\mathrm{l}) \rightarrow \mathrm{HI}_{3}(\mathrm{aq})
$$

We have insufficient data to fully elucidate how the catalytic activity changes as the reaction proceeds in a constant pressure experiment. We note that at low sulfuric acid concentrations essentially all of the iodine is present as $\mathrm{HI}$ and at high sulfuric acid concentrations essentially all the iodine is present as molecular iodine. Since the catalytic activity is maximized at intermediate acid concentrations we have incorporated the change in catalytic activity into the acid concentration term. Also note that we have replaced the $\mathrm{SO}_{2}$ term with the total pressure. Most of the system pressure is the $\mathrm{SO}_{2}$ pressure and the fit is slightly better using total pressure:

$$
\mathrm{r}=\mathrm{k} * \mathrm{f}(\mathrm{P}) * \mathrm{f}\left(\mathrm{H}_{2} \mathrm{SO}_{4} / \mathrm{H}_{2} \mathrm{O}\right) * \mathrm{f}\left(\mathrm{I}_{2}\right)
$$

Note that we use the $R$, the molar ratio of sulfuric acid to water as a measure of concentration as this best permits a function that asymptotes to zero at both small and large values of concentration with an intermediate maximum. The final best-fit empirical function for the rate of sulfur formation (using the Arrhenius constant and iodine concentration effect determined from the batch experiments) is:

$$
\mathrm{r}=\mathrm{k} * \mathrm{P}^{\alpha} * \mathrm{f}(\mathrm{R}) * \mathrm{C}_{\mathrm{I}_{2}}^{0.75}
$$


where $k=8.38 * e^{-7717 K / T} \frac{10^{7} \text { mole }}{\text { liter of aqueous solution } * h r}, P$ is measured in bar, $\alpha=0.537, C_{I_{2}}$ is the iodine concentration in moles per liter of aqueous solution and $f(R)=0.274+0.015 R+$ $\mathrm{e}^{-1052 *(\mathrm{R}-0.0942)^{2}}$

Figure 10(b) shows a comparison between the resulting model and the measured data for one run. A reasonably good agreements outlining the reaction rate as a function of time (acid concentration) was obtained considering all the runs. The model was used in the disproportionation reactor system design.

\section{Catalyst Recovery}

As $\mathrm{SO}_{2}$ disproportionation proceeds and $\mathrm{H}_{2} \mathrm{SO}_{4}$ concentration increases, some of the iodide anions oxidize to form elemental iodine. This is illustrated in Fig. 11 in which the acid gradually darkens as its concentration increases. Analysis showed the acid contains both elemental iodine and iodide ions whereas only iodine was found mixed in with elemental sulfur. It is imperative that the catalyst be recovered for reuse in order for the process to be cost effective. To accomplish this, the Bunsen reaction is employed. A two-step process is used to recover the catalyst from the acid solution. First, sulfuric acid is heated so elemental iodine is distilled from the solution due to it high vapour pressure. The vapour is condensed and regenerated into HI using $\mathrm{SO}_{2}$ and water. The distillation shifts the solution chemical equilibrium and prompts the dissolved iodide to oxidize into iodine according to the back Bunsen reaction. Figure 12(a) illustrates the concept. Upon heating, purple iodine vapour evaporates from the acid while the solution becomes more opaque due to iodine formation. The process of iodine removal during acid concentration (with heat) is shown in Fig. 12(b). The boiling temperature increases as the acid concentrates to $95 \mathrm{wt} \%$. All iodine species were completely extracted from the acid during 
concentration. Hence, the recovery procedure will be implemented as part of sulfuric acid concentration step within the process cycle.

To recover iodine from elemental sulfur, the forward Bunsen reaction is utilized. Molten sulfur is mixed with water under pressure and $\mathrm{SO}_{2}$ gas is bubbled through the mixture. Iodine is reduced to iodide which is soluble in the aqueous acid mixture. Figure 13(a) shows the results from sulfur scrubbing experiments at 120 and $180^{\circ} \mathrm{C}$ respectively. The Reaction is rapid and complete removal of iodine is achieved. Interestingly, iodine extraction is faster at the lower temperature. This is because the sulfur viscosity is significantly higher at $180^{\circ} \mathrm{C}$ which reduces mixing of the different phases and slows down iodine diffusion to the aqueous phase where the Bunsen reaction occurs. Figure 13(b) shows the appearance of post disproportionation sulfur before and after iodine removal.

\section{5. $\mathrm{SO}_{2}$ Disproportionation System Design}

A preliminary $\mathrm{SO}_{2}$ disproportionation processing scheme was established based on the kinetics equation and experimental data. To realize an all fluid process, the operating temperature will have to be maintained in the range $120-165^{\circ} \mathrm{C}$, in order to keep sulfur viscosity low. To maximize sulfur output, the design concept employs two continuous inline stirred reactors and their projected operating conditions are listed in Table 2. A schematic showing the proposed process scheme is shown in Figure 14. Both reactors will operate with a constant pressure of 600psig. Volume of the second reactor is approximately five times larger than the first one to account for the difference in reaction rates. The first reactor runs at a temperature between $160-165^{\circ} \mathrm{C}$ with an acid concentration between $30-35 \mathrm{wt} \%$. Fresh water, $\mathrm{SO}_{2}$ and iodide catalyst are fed into the reactor continuously to maintain a steady chemical composition. Under these conditions, the sulfur generation rate is at its maximum and the turnover rate (to produce 
the equivalent of amount the acid in the reactor at the same concentration) is less than an hour. Sulfur accumulates at the reactor bottom due to density difference and is withdrawn from tank via gravity. Based on data obtained to date, sulfur from the first reactor will be pure and contains no iodine. It will be washed and then dried for storage in either molten form or as solid. Acid from the first reactor is continuously fed into the second reactor, which operates between 120$125^{\circ} \mathrm{C}$. Even though the reaction will be slower, the lower system temperature will push disproportionation to its fullest extent. Additional catalyst may be added to speed up the reaction. With the higher catalyst content, the turnover in the second reactor is projected to be 5 hours or less. The size of this reactor is estimated to be four times larger than the first one. Sulfur will also be drawn from the bottom as in the first reactor but since elemental iodine is mixed in, it will need to be scrubbed. As iodine removal from sulfur is fast, the design concept utilizes a countercurrent reaction column. Sulfur flows in an opposite direction to $\mathrm{SO}_{2}$ and water at $150^{\circ} \mathrm{C}$. This will maximize contact between the different fluids and swiftly remove iodine from sulfur. The acid from the second reactor will be transferred to a boiler so it can be concentrated. Iodine will be distilled along with water and recovered for reuse. Testing of bench top prototypes is expected to provide data to finalize the process and reactor system design.

\section{Conclusions}

A sulfur-based thermochemical cycle that stores high temperature solar heat as elemental sulfur via the decomposition of $\mathrm{H}_{2} \mathrm{SO}_{4}$ and the disproportionation of $\mathrm{SO}_{2}$ was presented. The advantages of using this technology over molten salt based ones were outlined. A low storage cost of $\$ 2 / \mathrm{kWh}_{\mathrm{th}}$ and output heat at $1200^{\circ} \mathrm{C}$ were projected. The characteristics of $\mathrm{SO}_{2}$ disproportionation were studied using thermodynamics modeling and laboratory experiments. Modeling results revealed that the reaction can only take place under pressure. Reaction driving 
force is enhanced with system pressure and appropriate $\mathrm{H}_{2} \mathrm{O}: \mathrm{SO}_{2}$ ratios. On the other hand, the driving force is reduced with increasing temperature. Batch experiment results showed the reaction rate increases with temperature due to kinetics effect. The reaction rate and the extent of the disproportionation can be greatly enhanced by incorporating a homogenous iodide catalyst. Disproportionation can be completed in less than 3 hours by operating at $165^{\circ} \mathrm{C}$ with a high catalyst loading. The dependence of disproportionation rate on sulfuric acid concentration was also determined via constant pressure experiments. The fastest reaction was found between $30-$ $35 \mathrm{wt} \% \mathrm{H}_{2} \mathrm{SO}_{4}$ and this is due to the formation of $\mathrm{I}_{3}{ }^{-}$anions acting as the catalytic species. The forward and reverse Bunsen reactions were employed to recover the catalyst from molten sulfur and sulfuric acid respectively. Modelling and test data were used to establish a design concept for a $\mathrm{SO}_{2}$ disproportionation reactor system. Two inline reactors operating at 120 and $165^{\circ} \mathrm{C}$ are used to maximize sulfur generation and the final acid concentration. This system is designed as part of the overall sulfur based thermochemical energy storage technology for use with concentrated solar power plant.

\section{Acknowledgements}

This material is based upon work supported by the U.S. Department of Energy, Office of Science, Office of Fusion Energy Sciences, under Grant DE-EE0003588. The paper is dedicated to the memory of Dr. Gottfried Besenbruch. 


\section{References}

[1] P. Denholm, Y.-H. Wan, M. Hummon, and M. Mehos, Energy Procedia 49 (2014) 16221631

[2] S. Wagner and E. Rubin, Renewable Energy, 61 (2014) 81-95

[3] R. Sioshansi and P. Denholm, NREL Technical Report, (2010) TP-6A2-45833

[4] R. Buckingham, L. Brown, and B. Wong, "Sulfur Based Thermochemical Heat Storage for Baseload Concentrating Power," CSP Subprogram Review, Golden, CO, (2011)

[5] A. Broggi et al. Decomposition of sulfuric acid by the Cristina process-A status report. in Hydrogen Energy Progress 2. 1982. New York: Pergamon Press

[6] JRC Ispra, Technological Circuit for the Thermochemical Decomposition of Sulphuric Acid CRISTINA Process and CHRIS Pilot Plant, EUR 11229 EN/I. 1987, JRC: Ispra

[7] A.Noglik et al., International Journal of Energy Research, (2009) 33(9): p. 799-812

[8] C.S. Kim et al., International Journal of Hydrogen Energy, (2008) 33: p. 3688 - 3699

[9] Gelbard, F., R. Moore, and E. Parma, Status of Initial Testing of the $\mathrm{H}_{2} \mathrm{SO}_{4}$ Section of the ILS Experiment. (2007), Sandia National Laboratories

[10] A. Terada, Journal of Nuclear Science and Technology, (2007). 44(3): p.477-482

[11] J. Norman, J..Russell, J. Porter, K. McCorkle, T. Roemer and R. Sharp, Process for the thermochemical production of hydrogen, U.S. Patent 4089940A 1978

[12] E. Bilgen, Solar Energy, (1988) 41(2): p. 199-206

[13] M. Roeb, et al, International Journal of Nuclear Hydrogen Production and Applications, (2011) 2(3) 202-26

[14] D. Thomey, L. de Oliveira, J.-P. Saeck, M. Roeb, and C. Sattler, International Journal of Hydrogen Energy (2012) 37(21) 16615-16622 
[15] GA Atomics Staff, "Decomposition of Sulfuric Acid using Solar Thermal Energy," General Atomics Report GA-A17573 (1985)

[16] SOL2HY2 (Solar to Hydrogen Hybrid Cycles): https://sol2hy2.eucoord.com/

[17] S. Oana and Ishikawa, Geochemical Journal 1(1) (1966) 45-50

[18] M. Kusakabe, Y. Komoda, B. Takano, and T. Abiko, Journal of Volcanology and Geothermal Research (2000) 97 pp.287-307

[19] M. Gorensek, J. Staser, T. Stanford, and J. Weidner, International Journal of Hydrogen Energy 34(15) (2009) pp.6089-6095

[20] E. Loshchilova and B. Karvaly, Chemistry and Physics of Lipids 19 (1977) 159-168

[21] B. Meyer, I. Ospina, and L.B. Peter, Analytica Chimica Acta. 117 (1980) 301-311

[22] M. A. Hooper and D.W. James, Spectrochimica Acta 26A (1969) 669-670

[23] M. Ishibashi, Y. Yamamoto and Y. Inoue, Bulletin of the Institute for Chemical Research, Kyoto University (1959) 37(1) 1-7

[24] T. Doi, Rev. Phys. Chem. Japan 33 (1963) 41-52

[25] V. Petruševski, M. Bukleski, and M. Stojanovska, Journal of Laboratory Chemical Education 1 (2013) 1-4 


\section{List of Figure Captions}

Fig. 1. The sulfur based thermochemical cycle for thermal energy storage.

Fig. 2. Effect of (a) system pressure, temperature and (b) $\mathrm{H}_{2} \mathrm{O}: \mathrm{SO}_{2}$ ratio on sulfur produced by $\mathrm{SO}_{2}$ disproportionation.

Fig. 3. Effect of temperature and $\mathrm{H}_{2} \mathrm{O}: \mathrm{SO}_{2}$ ratio on (a) $\mathrm{H}_{2} \mathrm{SO}_{4}$ concentration and (b) $\mathrm{SO}_{2}$ to $\mathrm{S}$ conversion. (c) Effect of pressure and temperature on $\mathrm{H}_{2} \mathrm{SO}_{4}$ concentration. Lines are modeling results and experimental data points are included in the plots.

Fig 4. (a) Test cell containing water with dissolved iodide catalyst. (b) Parr pressure vessel set up for conducting batch $\mathrm{SO}_{2}$ disproportionation experiments.

Fig. 5. (a) Constant pressure test system setp up. (b) Pressure profiles for batch and constant pressure experiments.

Fig. 6. (a) and (b) Effect of iodide and other catalysts on $\mathrm{SO}_{2}$ disproportionation rate.

Fig. 7. Effect of (a) various iodide salts and (b) hydrogen iodide loading and temperature on disproportionation rate. (c) Calculated vs. measured sulfur weight.

Fig 8. (a) Calculated $\mathrm{H}_{2} \mathrm{SO}_{4}$ conc. and instantaneous reaction rates during a constant pressure experiment $\left(610 \mathrm{psig}, 150^{\circ} \mathrm{C}, \mathrm{I} / \mathrm{H}_{2} \mathrm{O}=0.17 \%\right)$. (b) Dependence of reaction rate on acid concentration derived from least square fit of all constant pressure experiment data.

Fig. 9. Raman spectra of a disproportionation sample at $t=0,4.4$ and 10hours respectively. Fig. 10 . (a) Effect of constant pressure on acid concentration and disproportination completion time. (b) Comparison between the rate model and data from one constant pressure run.

Fig. 11. Evolution of a test cell during $\mathrm{SO}_{2}$ disproportionation. Sulfuric acid conc. is at (a) $32 \mathrm{wt} \%$, (b) $53 \mathrm{wt} \%$ and (c) $58 \mathrm{wt} \%$. 
Fig. 12. (a) Distillation of post disproportionation sulfuric acid. (b) Iodine species and the boiling temperature (distillation) of the acid products.

Fig 13. (a) Iodine concentration in sulfur as a function of scrubbing time. (b) Sulfur before and after scrubbing.

Fig 14. A schematic showing the concept to carry out $\mathrm{SO}_{2}$ disproportionation utilizing two in series stirred reactors. 


\section{List of Figures}

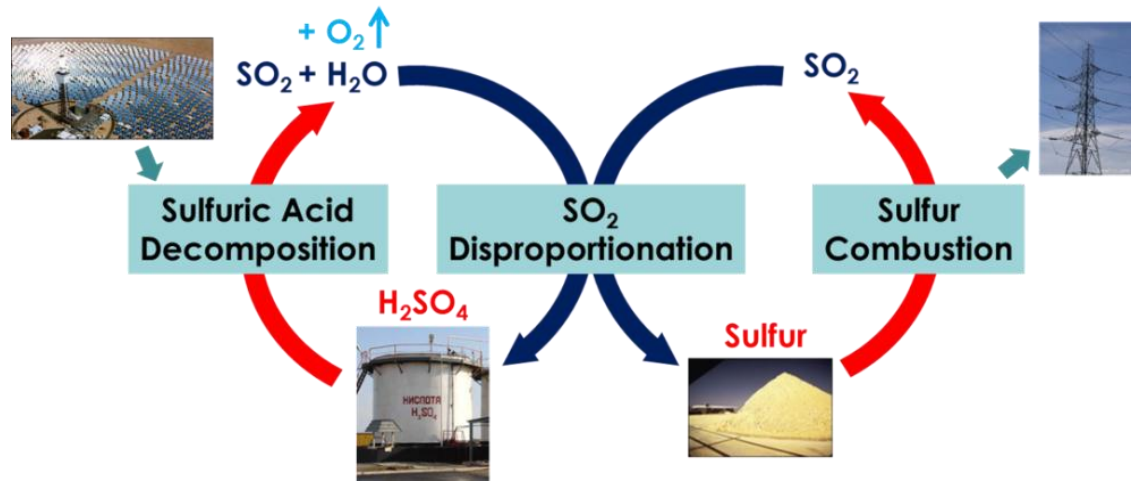

Fig. 1 


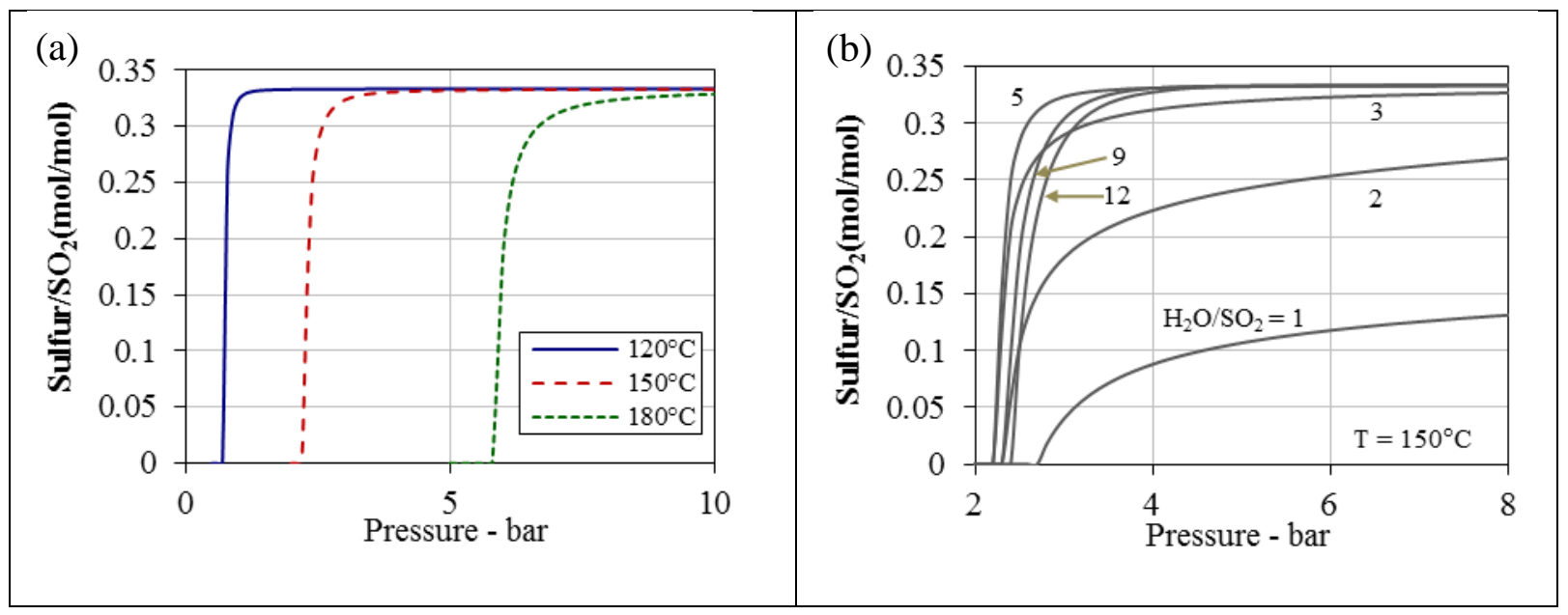

Fig. 2 

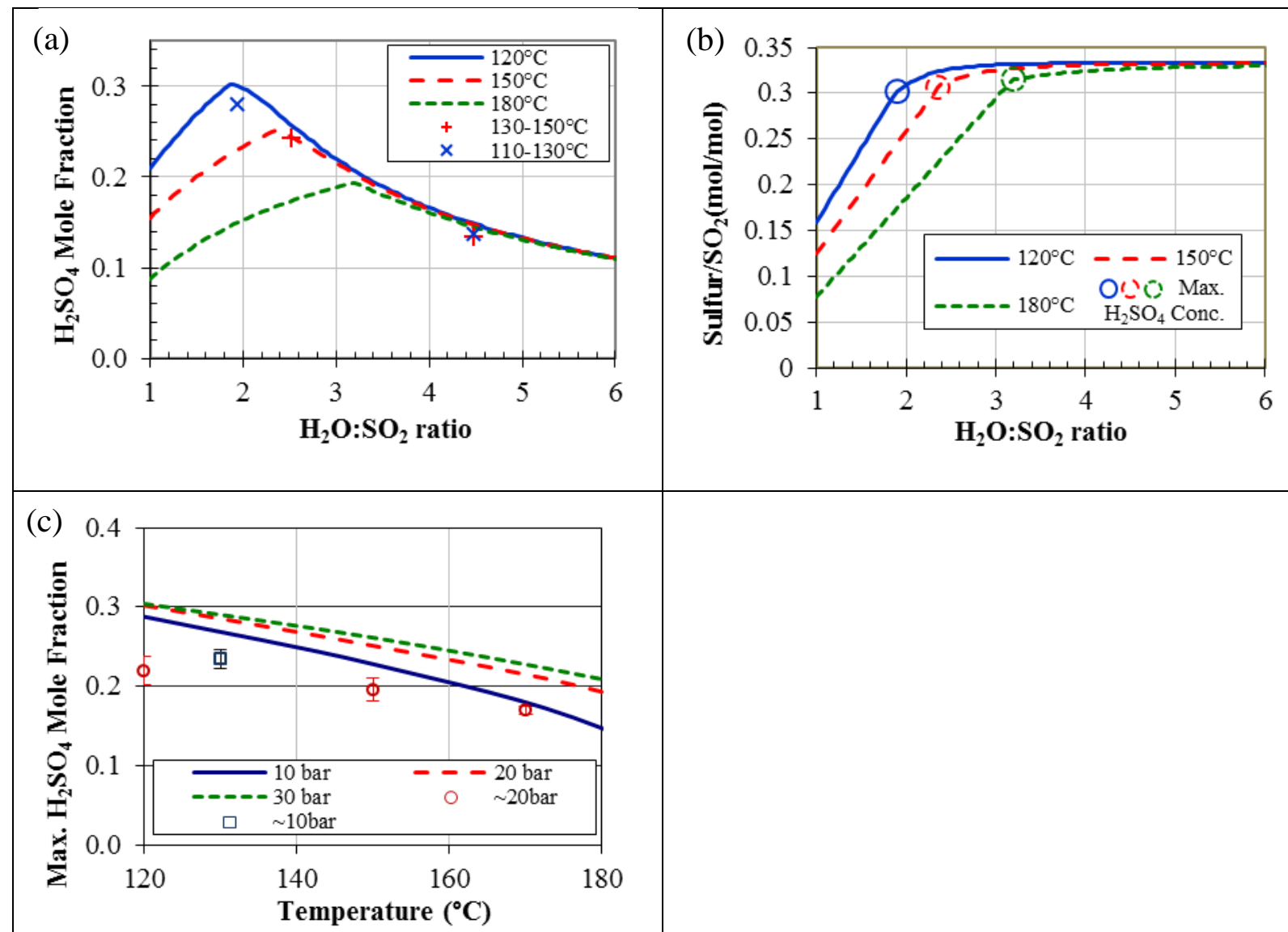

Fig. 3 


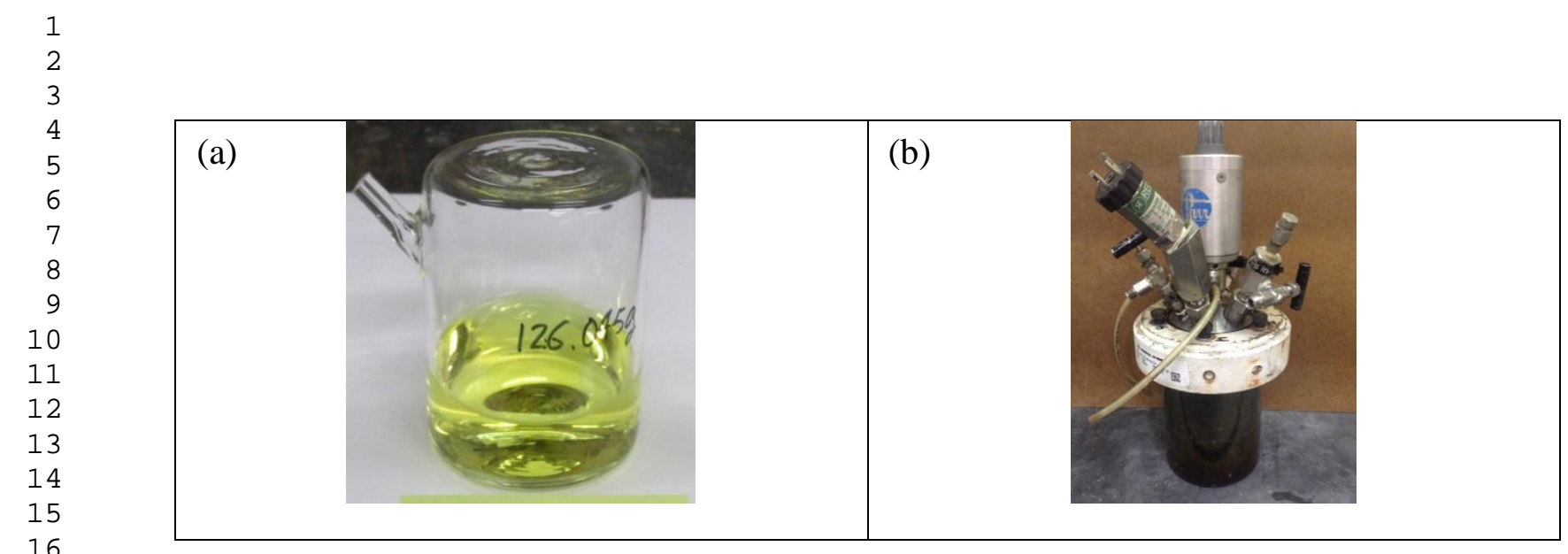

Fig. 4 

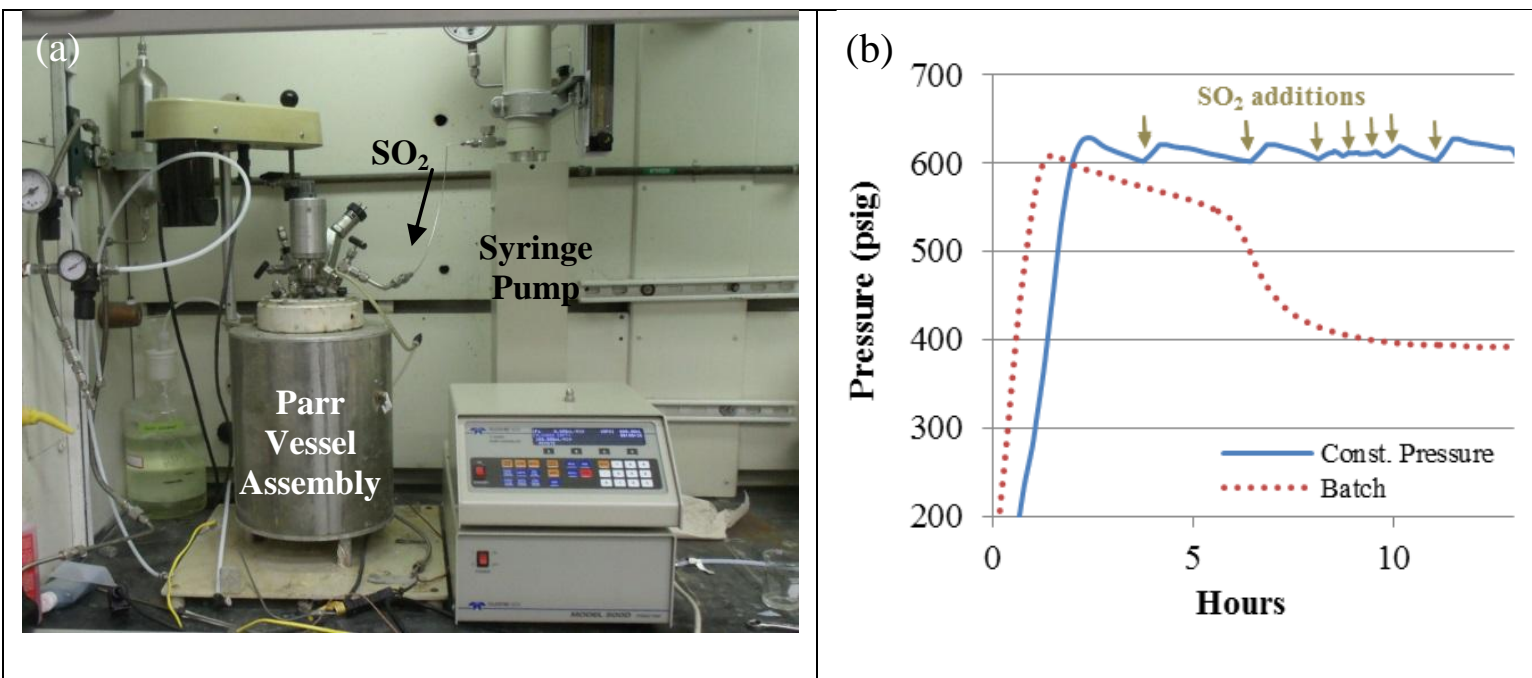

Fig. 5 


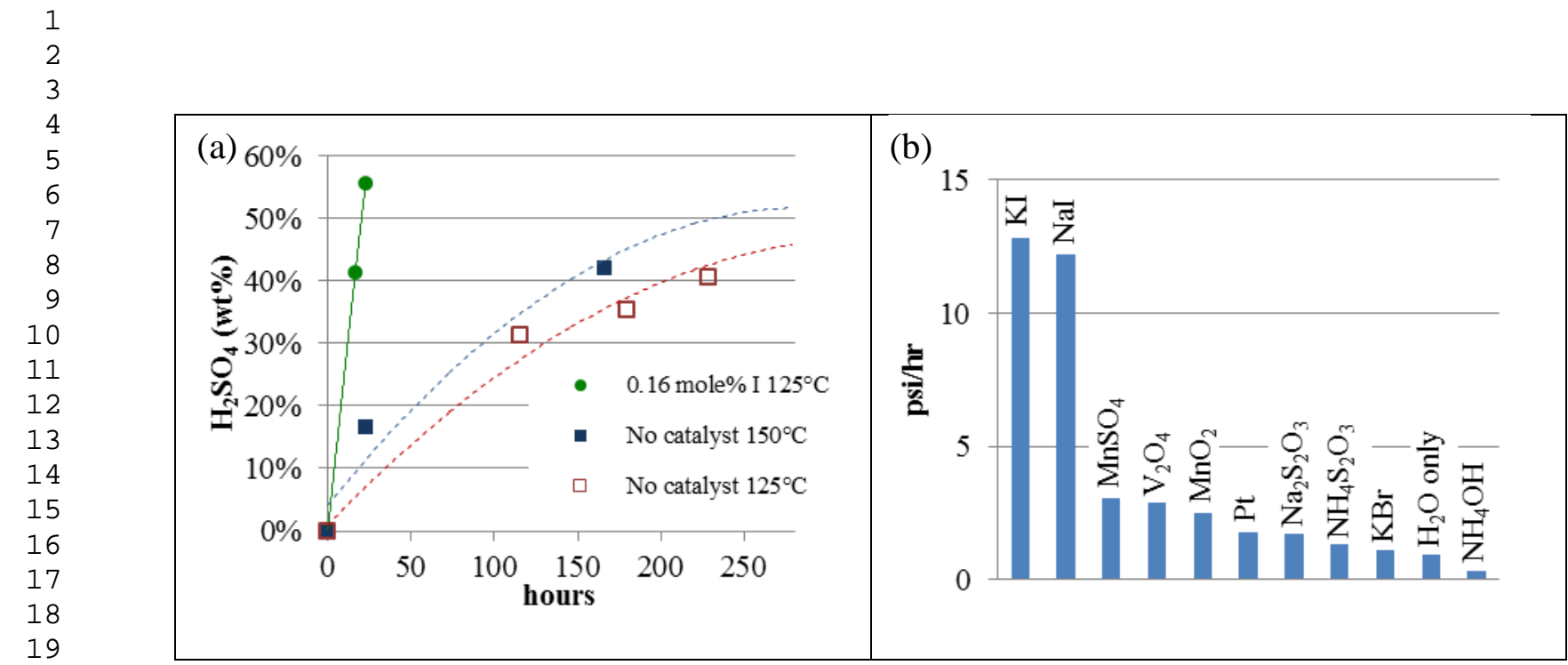

Fig. 6 

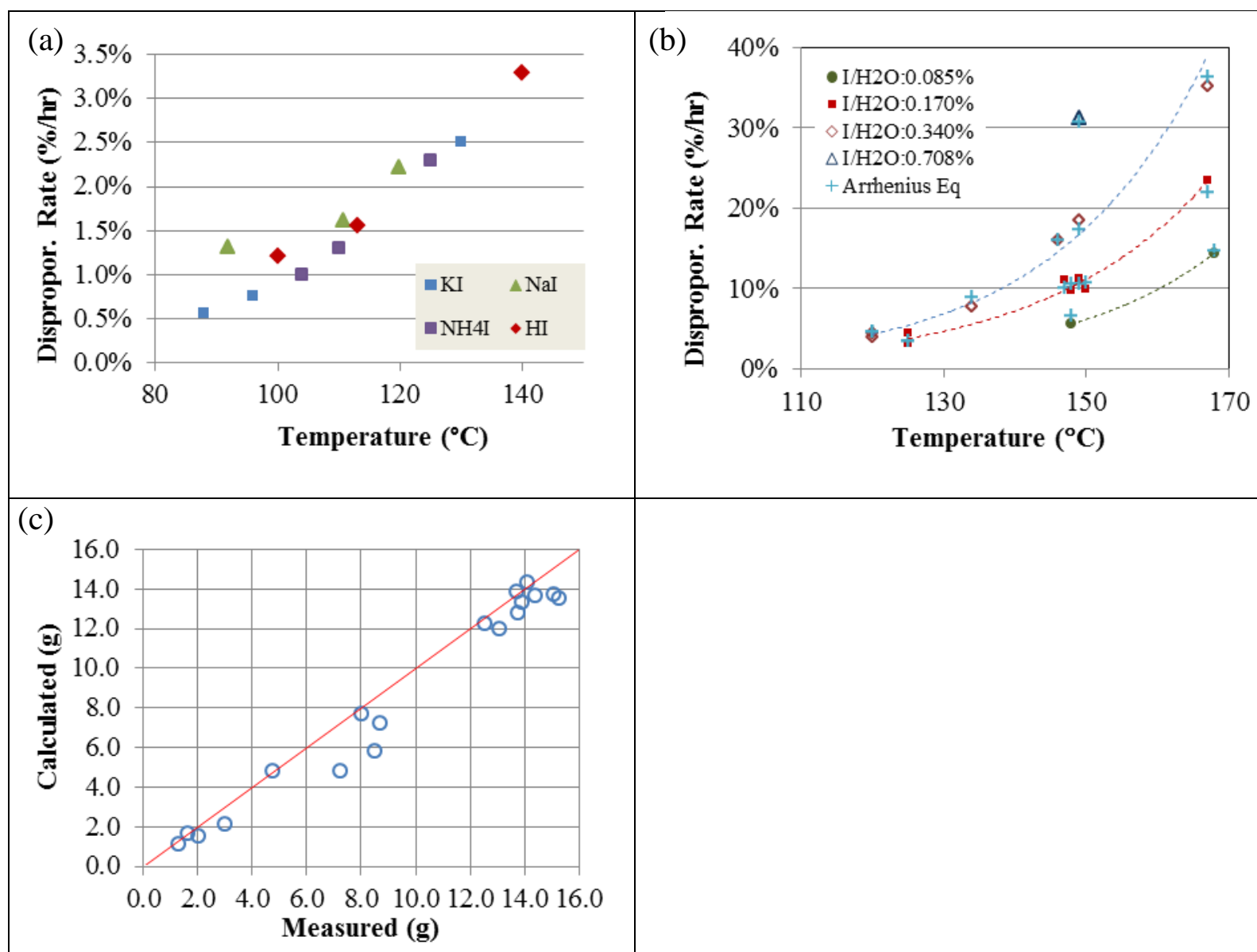

Fig. 7 


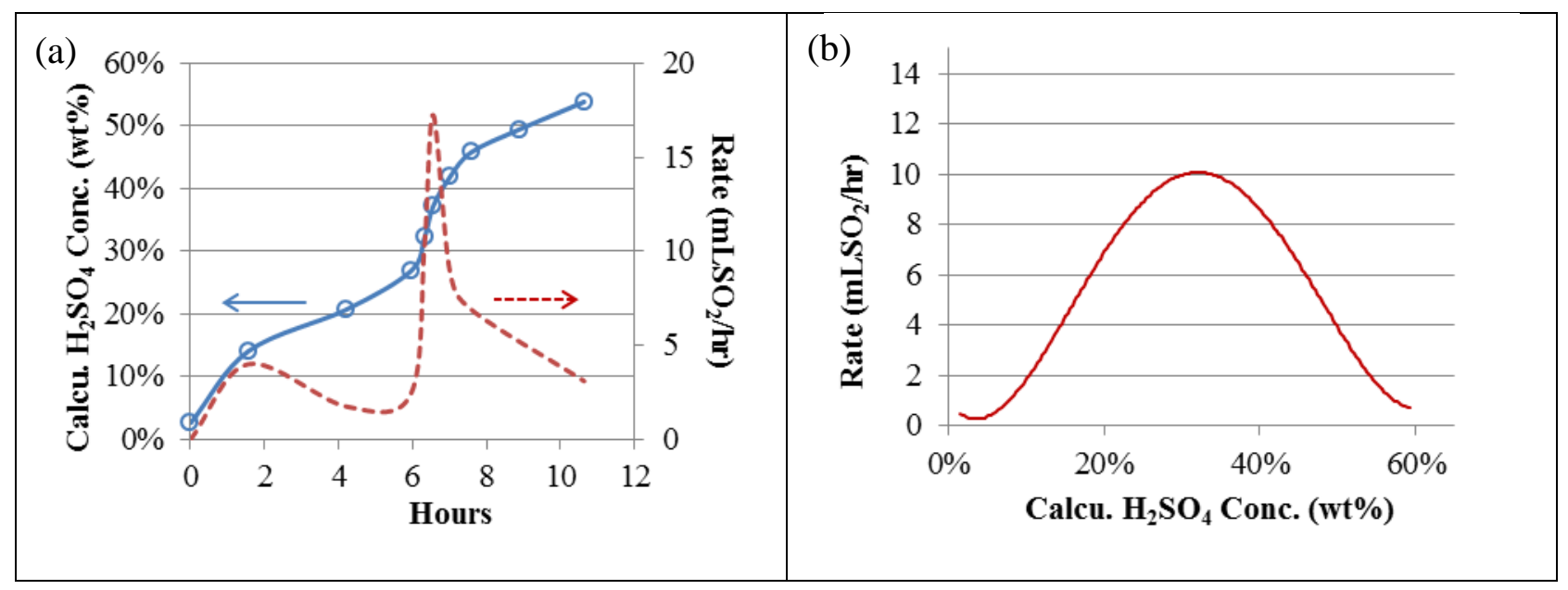

Fig. 8

22

23 


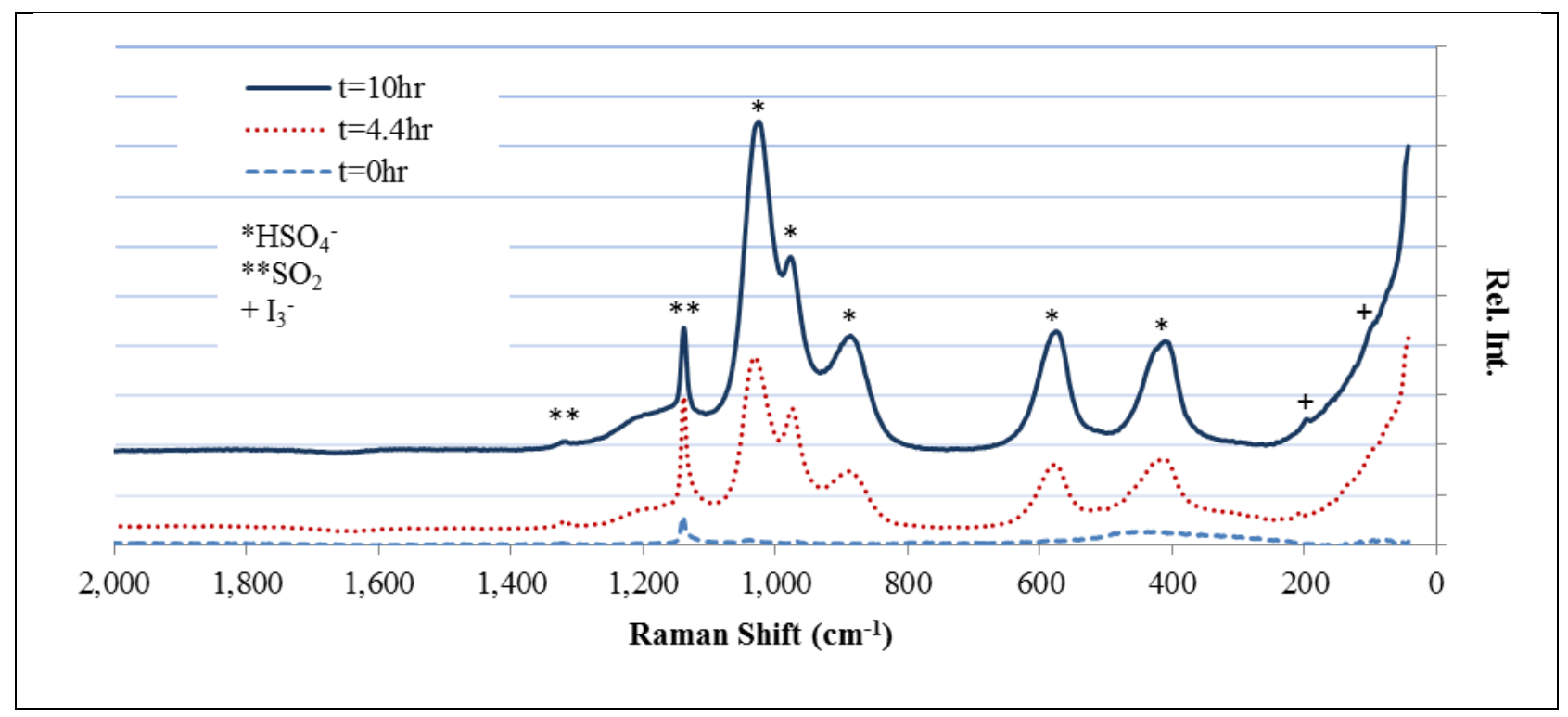

Fig. 9 


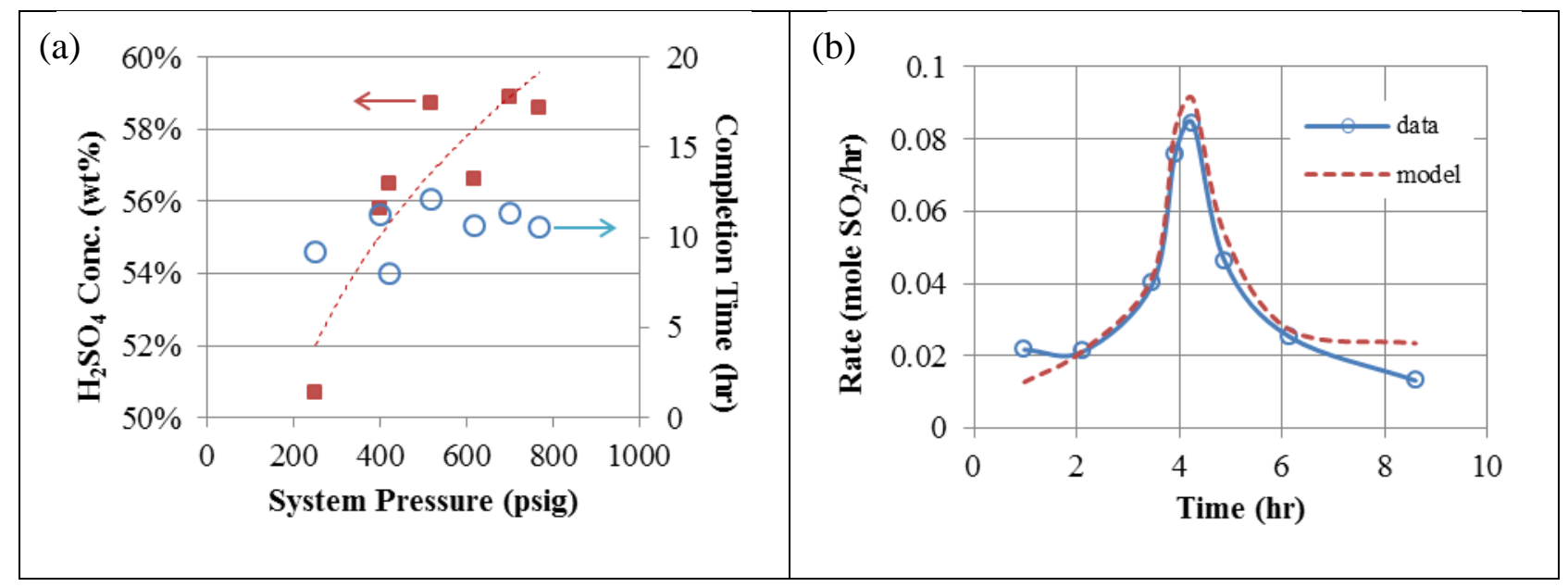

Fig. 10

23

24

25 


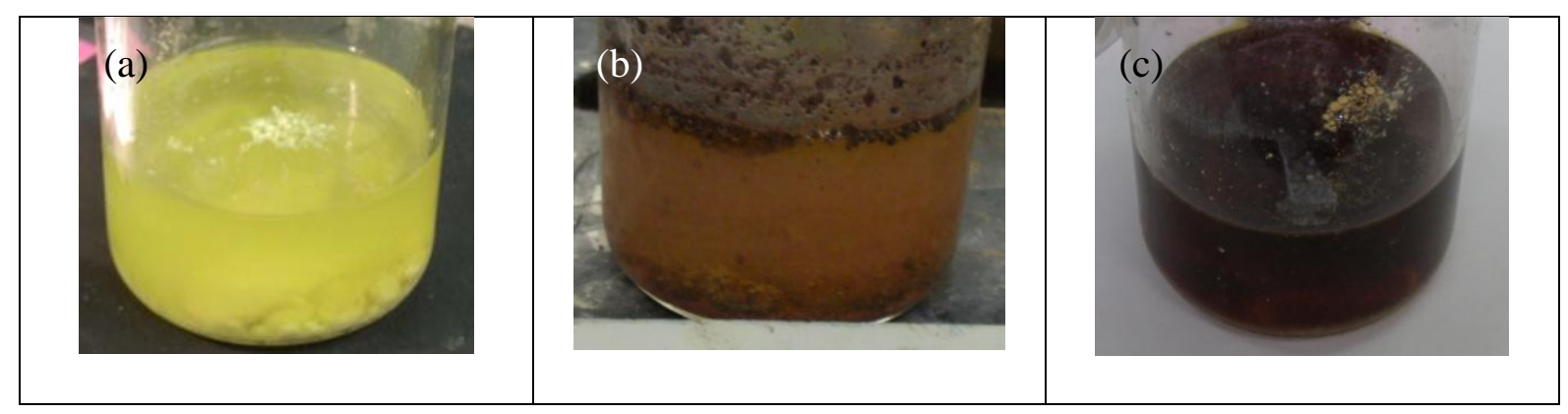

Fig. 11 


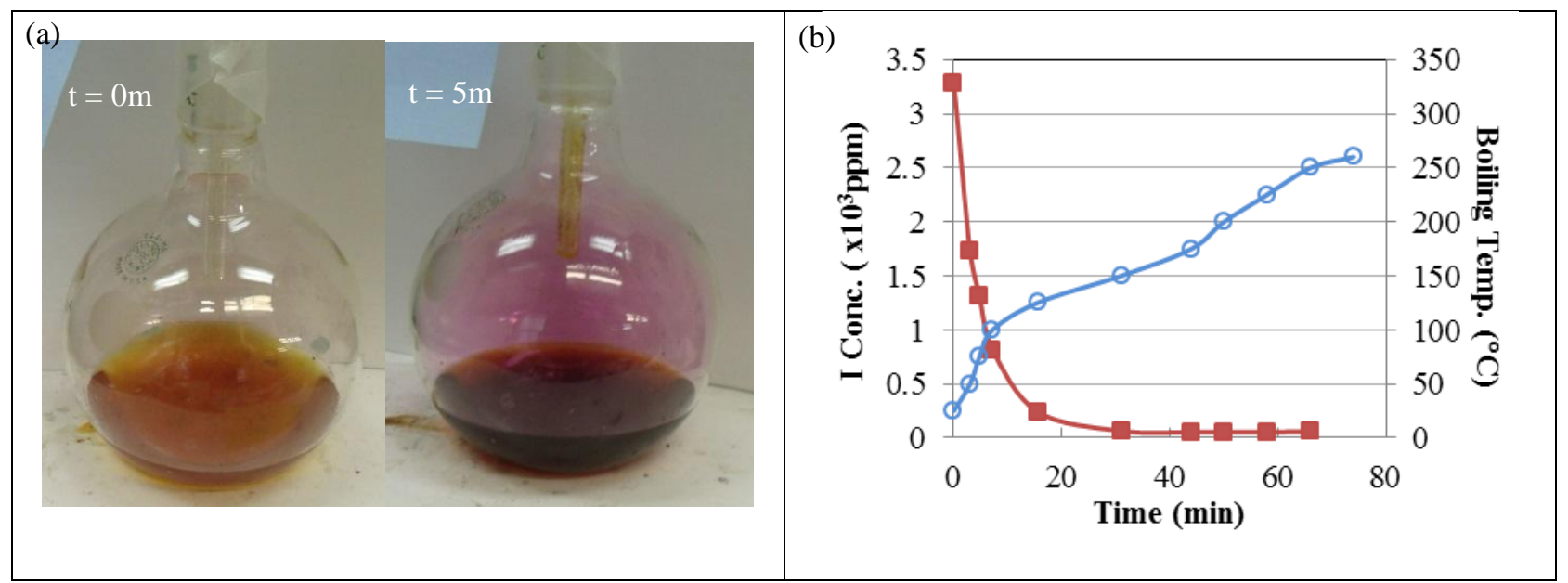

Fig. 12

23

24

25

26

27

28

29

30

31

32

33

34

35

36

37

38

39

40

41

42

43

44

45

46

47

48

49

50

51

52

53

54

55

56

57

58

59

60

61

62 


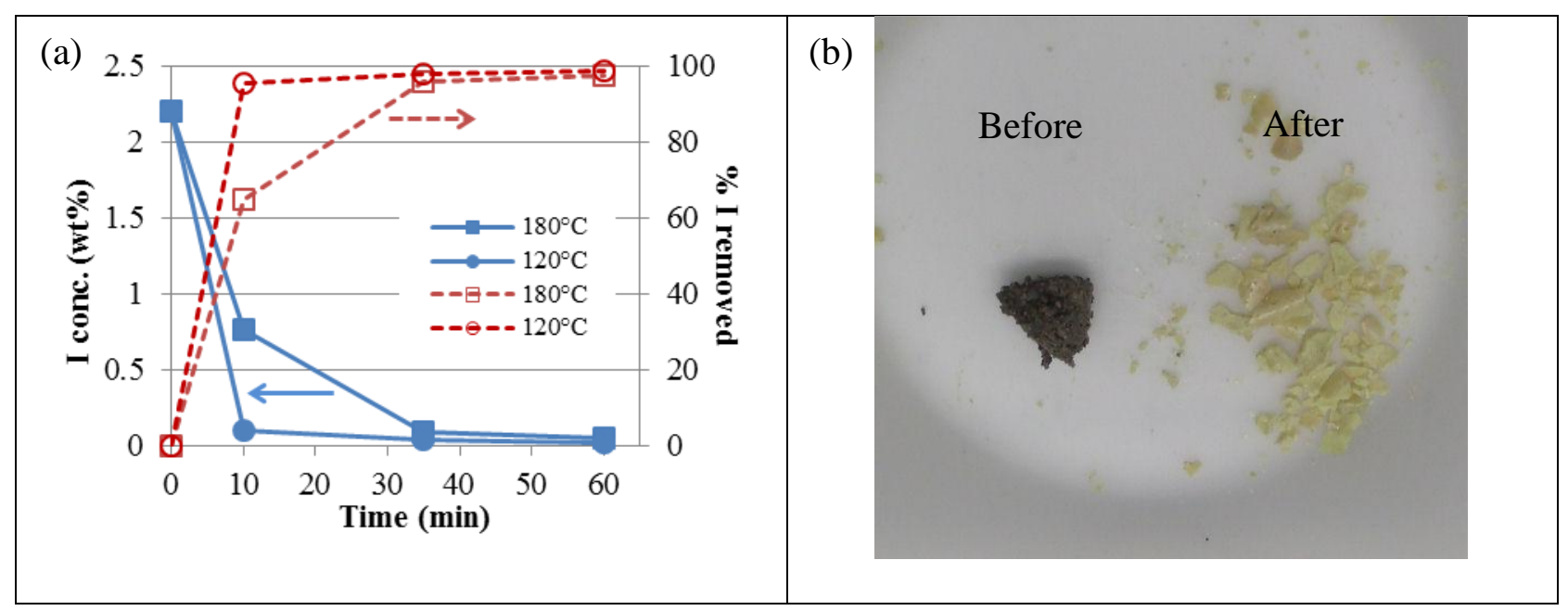

Fig. 13 


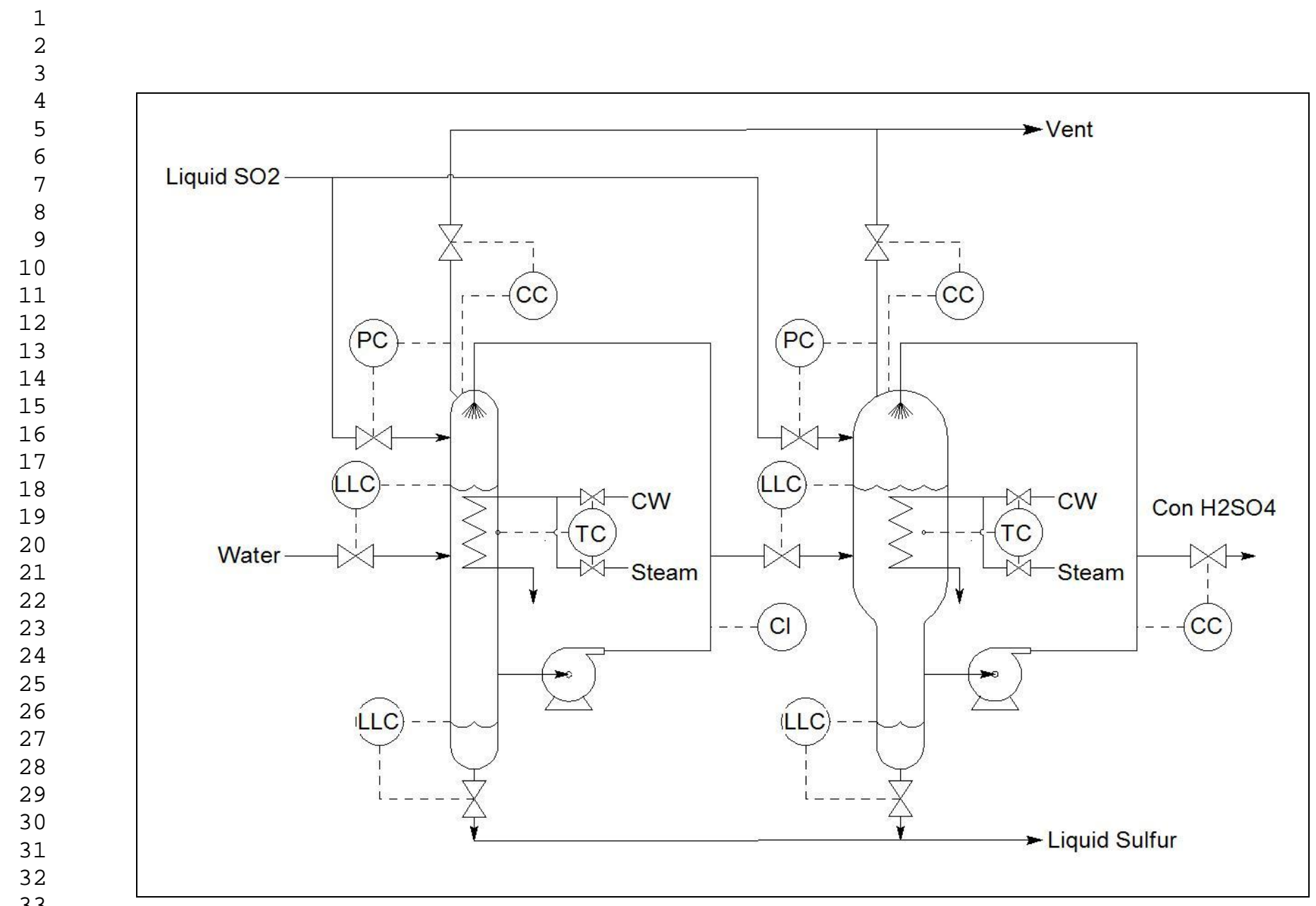

Fig. 14 


\section{List of Table Captions}

Table 1. A comparison between using sulfur and molten salt as TES medium.

Table 2. Process conditions for the in-line disproportionation reactors. 


\section{List of Tables}

Table 1

\begin{tabular}{|c|c|c|}
\hline & Sulfur & Molten Salt \\
\hline Specific Energy (kJ/kg) & 9281 & 282 \\
\hline Raw Materials (\$/Mton) & 60 & 500 \\
\hline Materials Cost $(\$ / \mathrm{kWh})$ & 0.025 & 5.8 \\
\hline Cost of Storage $(\$ / \mathrm{kWh})$ & 2 & 30 \\
\hline Input Temp $\left({ }^{\circ} \mathrm{C}\right)$ & $600-900$ & $550(\max )$ \\
\hline Max. Output Temp $\left({ }^{\circ} \mathrm{C}\right)$ & 1200 & 550 \\
\hline Melting Point & 115 & 308 \\
\hline LCOE w/ Rankine ( $\varnothing / \mathrm{kWh})$ & $13-15$ & 14 \\
\hline LCOE w/ Combined Cycle ( $\varnothing / \mathrm{kWh})$ & $6-8$ & NA \\
\hline Capacity Factor* & $>75 \%$ & $40-60 \%$ \\
\hline Charging and Discharging Kinetics & Fast & Fast \\
\hline Ambient Storage & yes & no \\
\hline Seasonal Storage & yes & no \\
\hline
\end{tabular}

*(Actual Power Output)/(Full Nameplate Capacity) of a power plant 
Table 2

\begin{tabular}{lcc}
\hline & Reactor 1 & Reactor 2 \\
\hline Temperature $\left({ }^{\circ} \mathrm{C}\right)$ & $160-165$ & $120-125$ \\
\hline Acid Conc. $(w t \%)$ & $30-35$ & $55-60$ \\
\hline Catalyst $\left(\mathrm{I} / \mathrm{H}_{2} \mathrm{O}\right.$ mole \%) & $0.5-0.8$ & 0.80 \\
\hline Pressure (psig $\left.-\mathrm{SO}_{2}\right)$ & 600 & 600 \\
\hline Turnover $(\mathrm{hr})$ & 1 & 5 \\
\hline
\end{tabular}


List of Figures

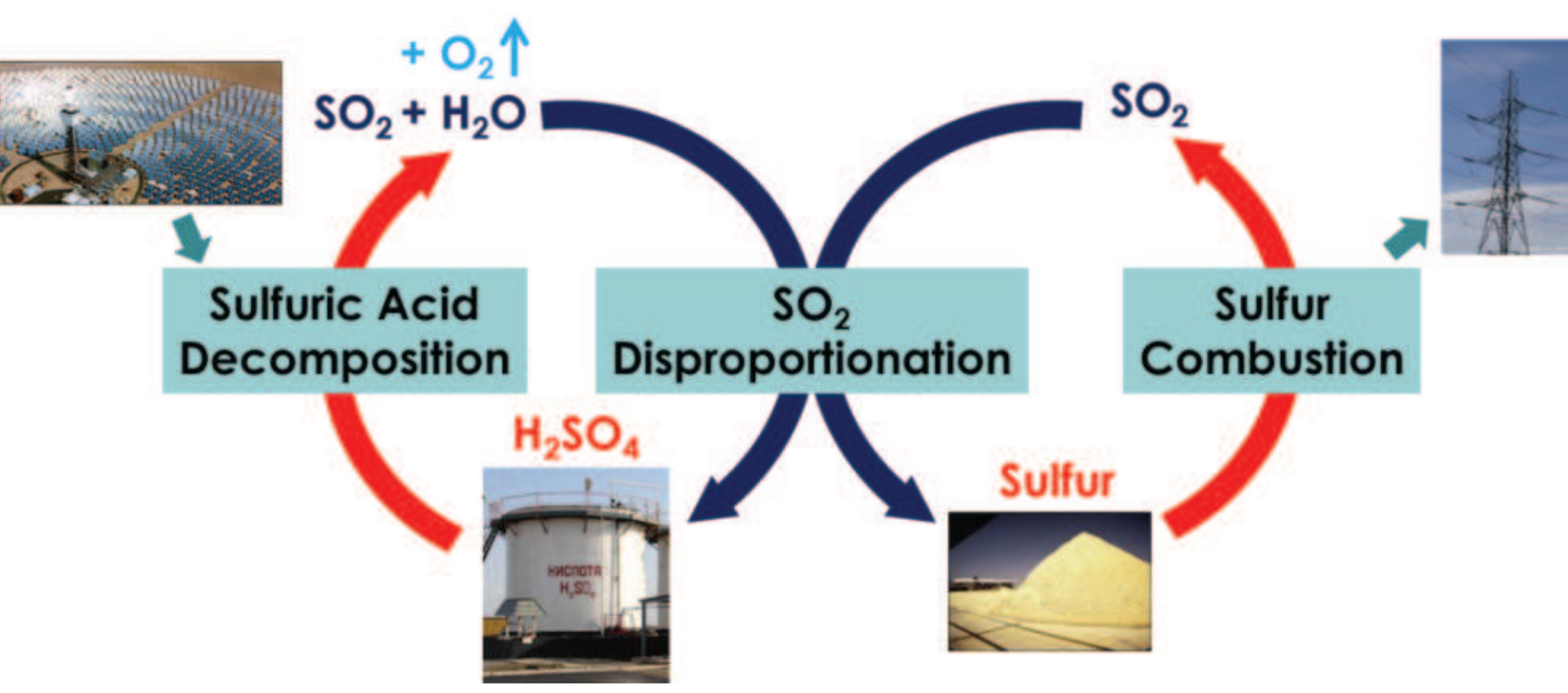

Fig. 1 

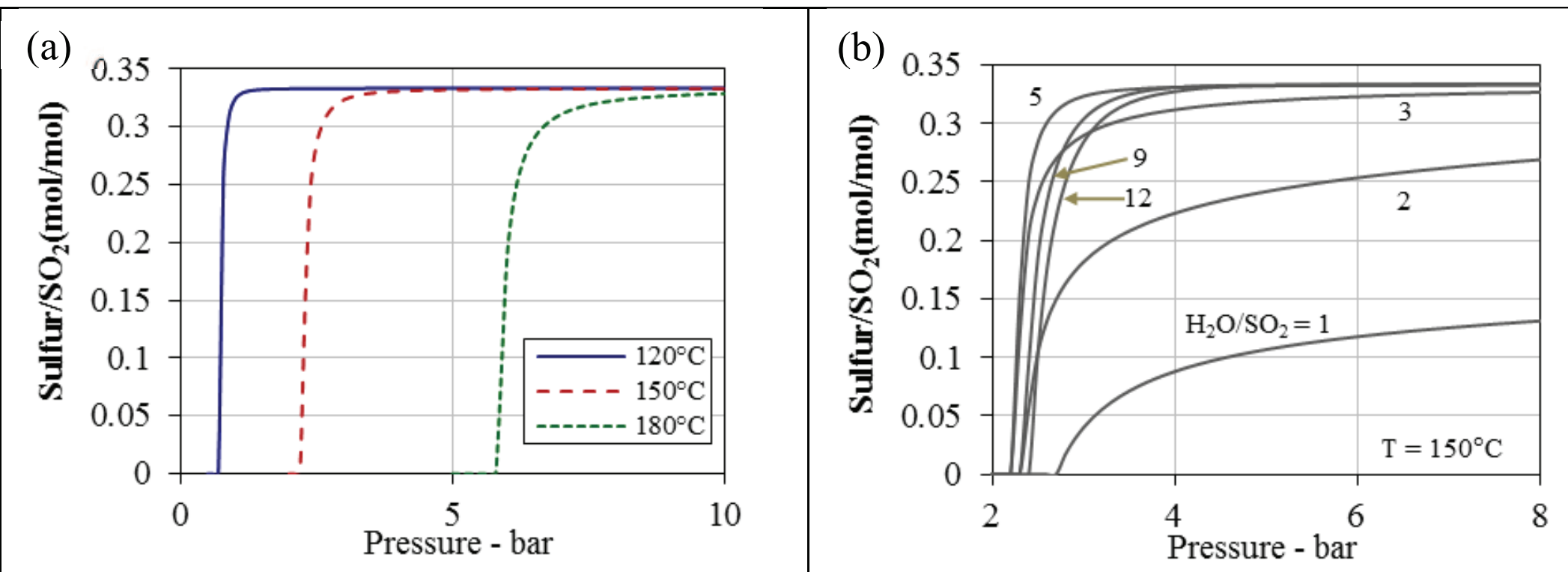

Fig. 2 

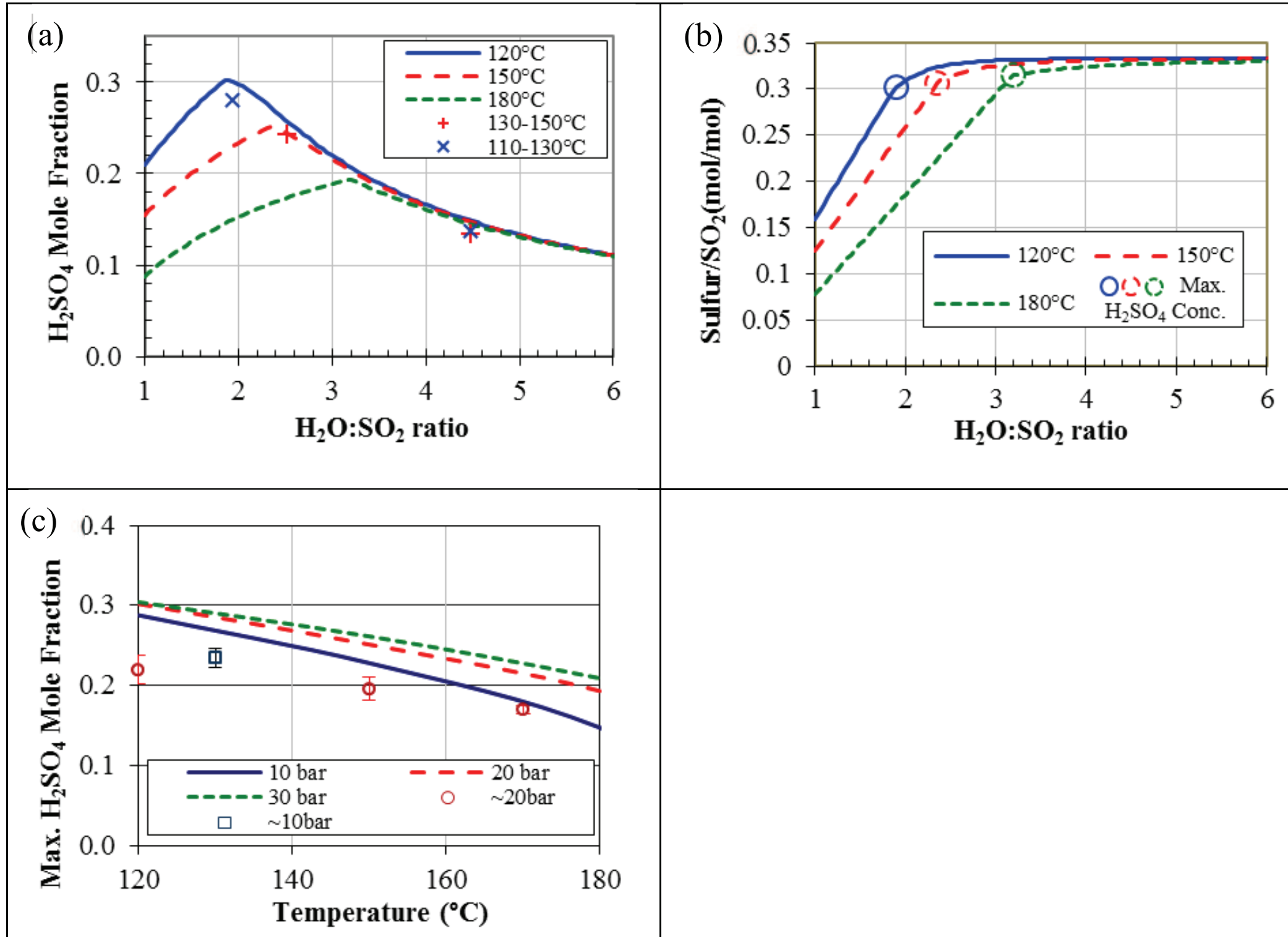

Fig. 3 
(a)

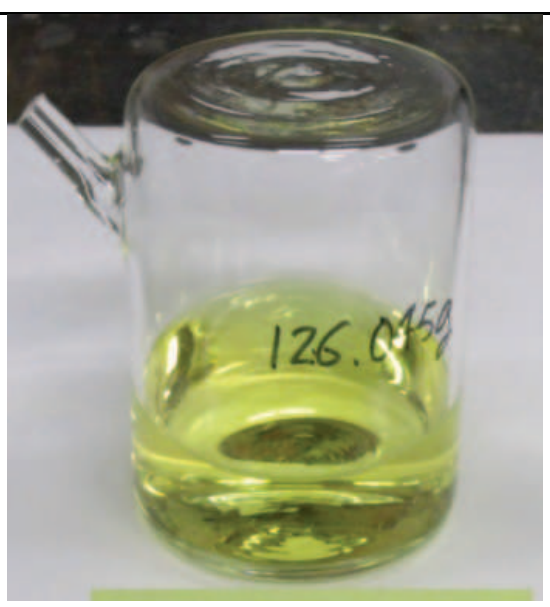

(b)

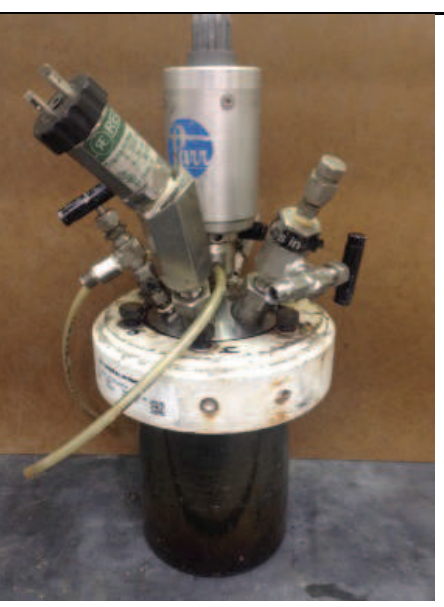

Fig. 4 


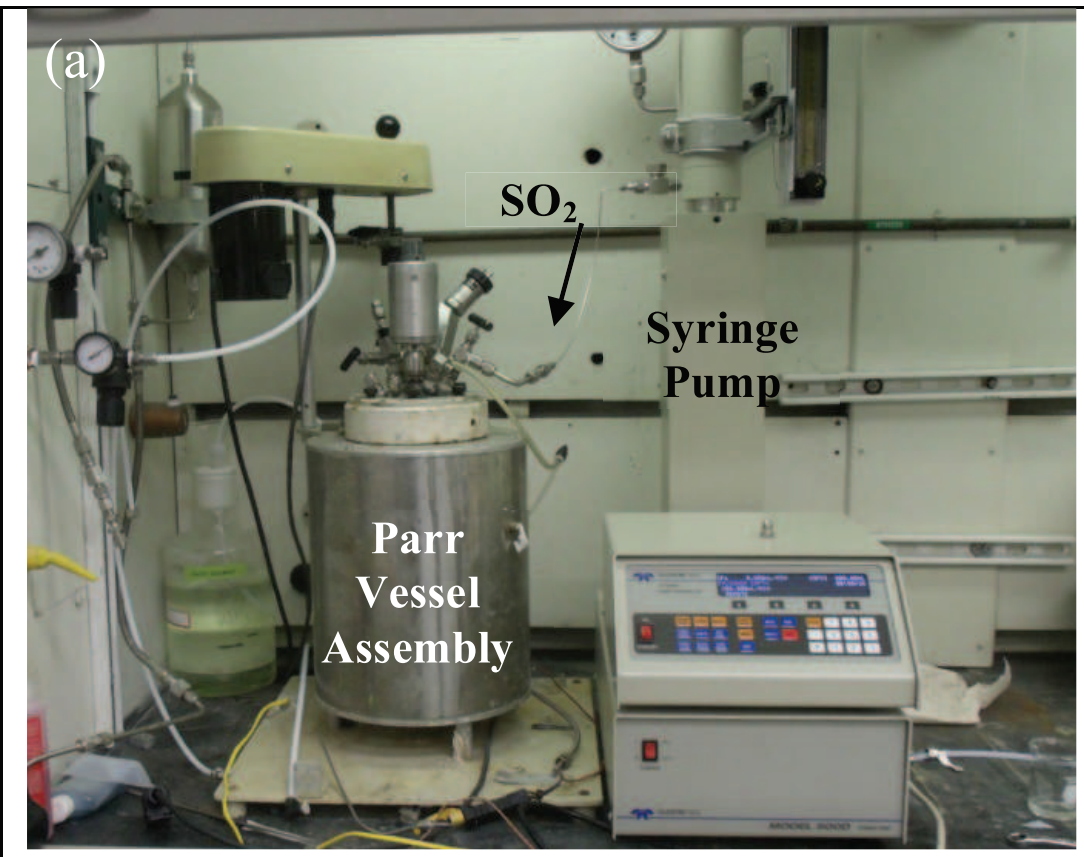

(b)

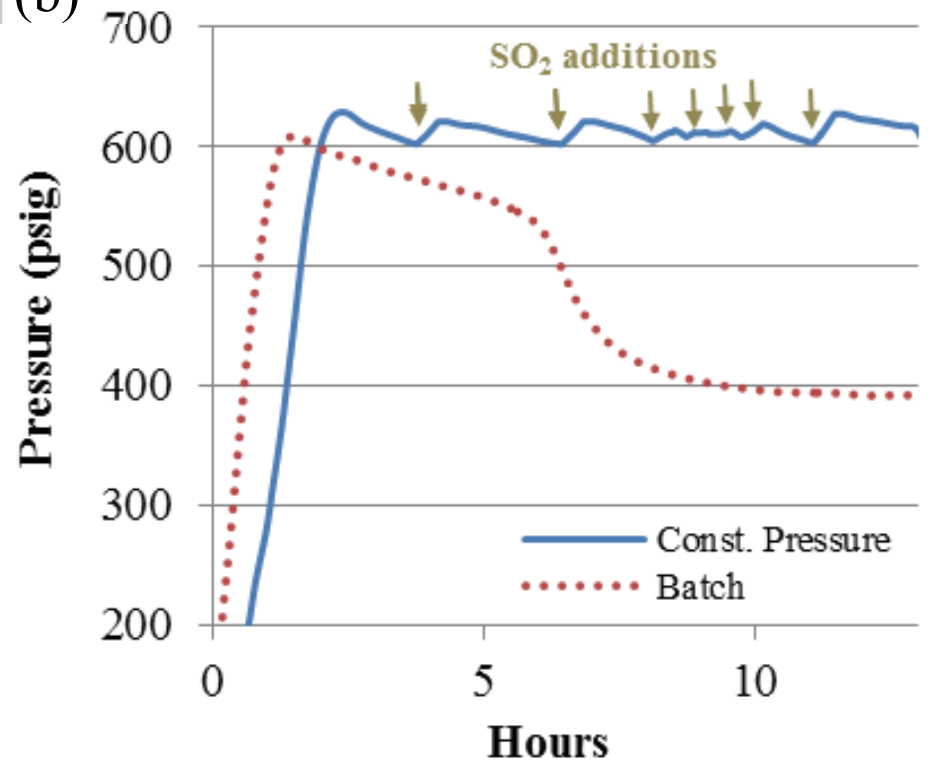

\section{Fig. 5}




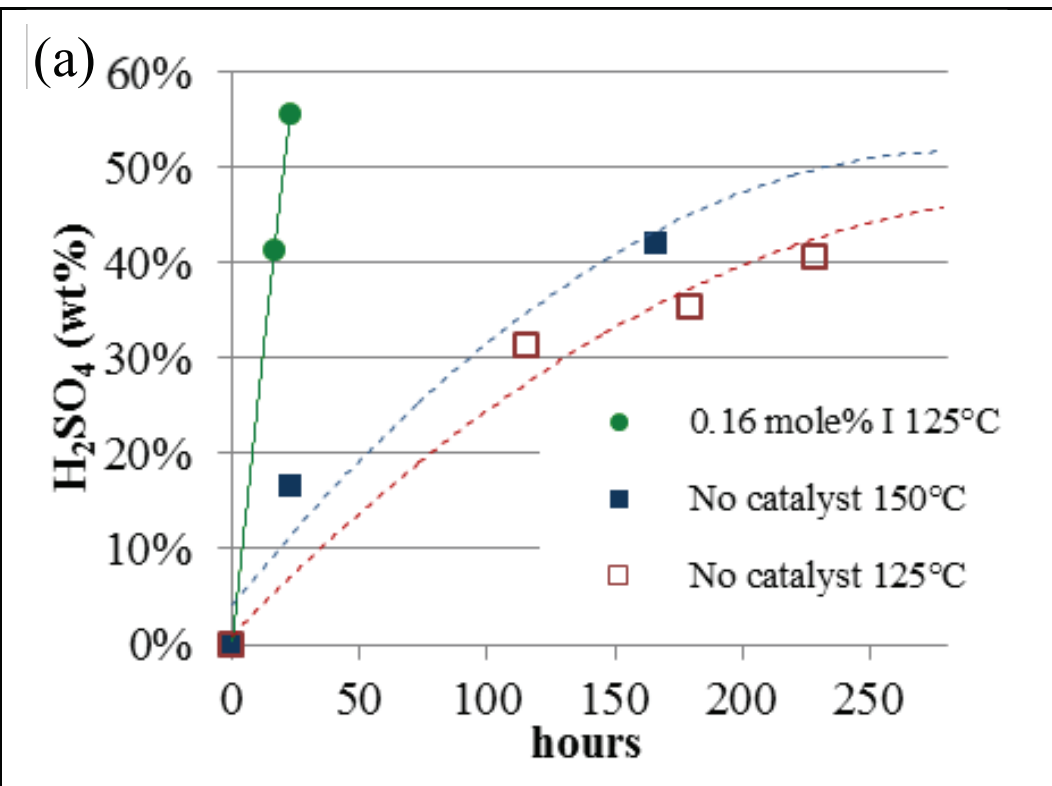

(b)

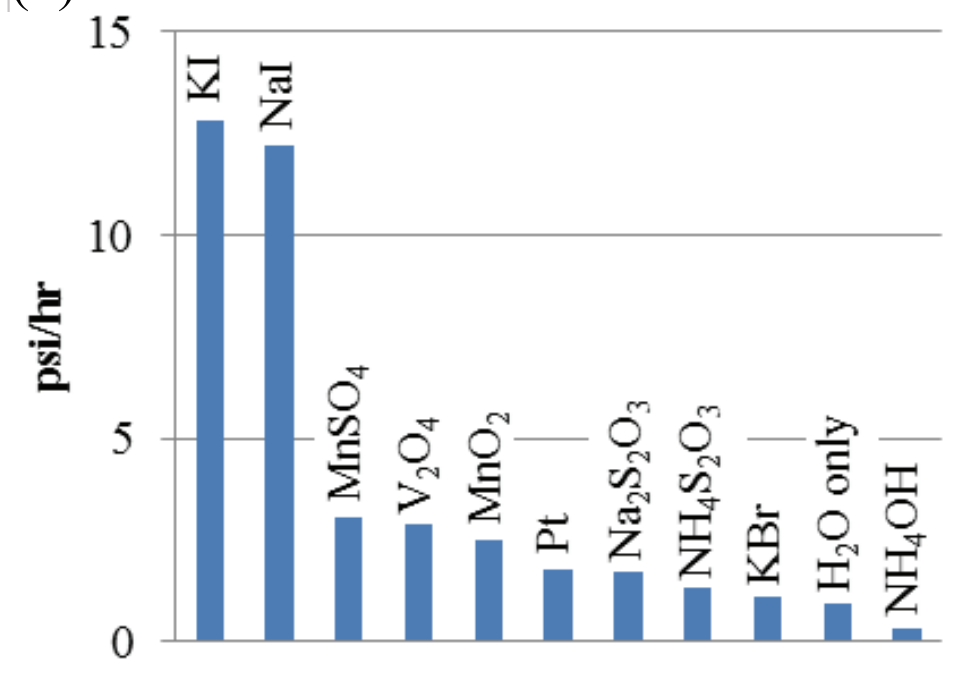

Fig. 6 

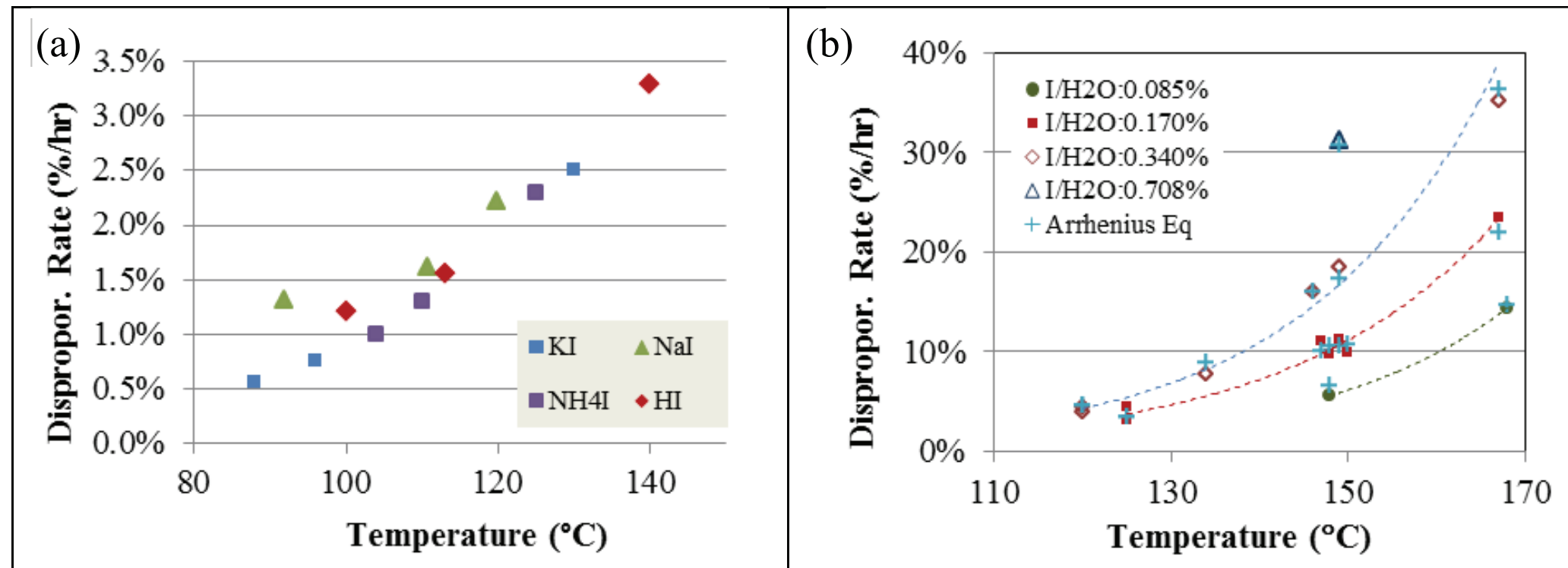

(c)

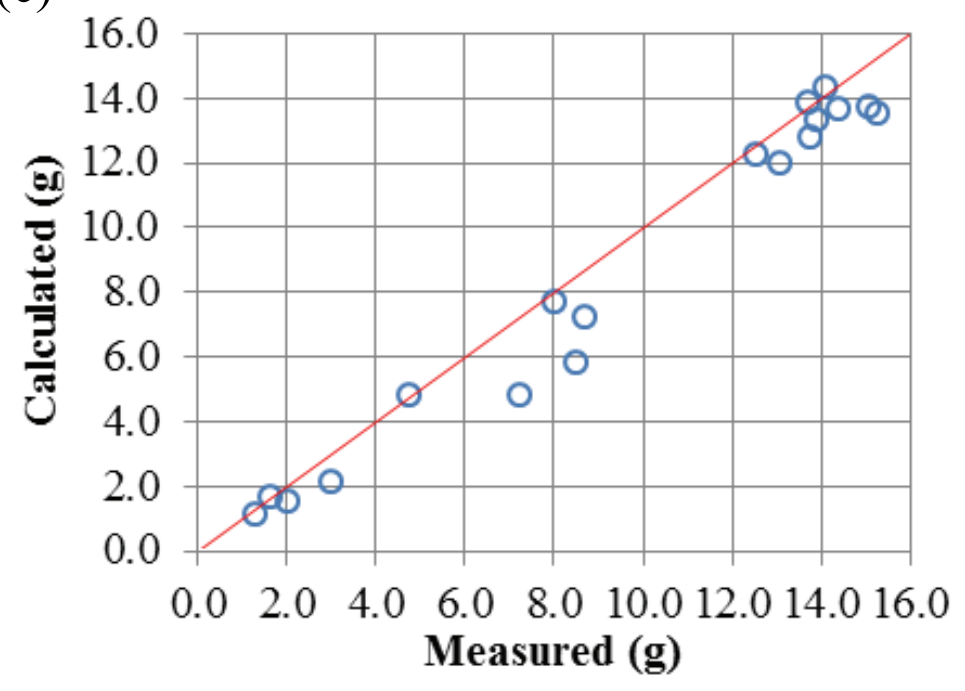

Fig. 7 


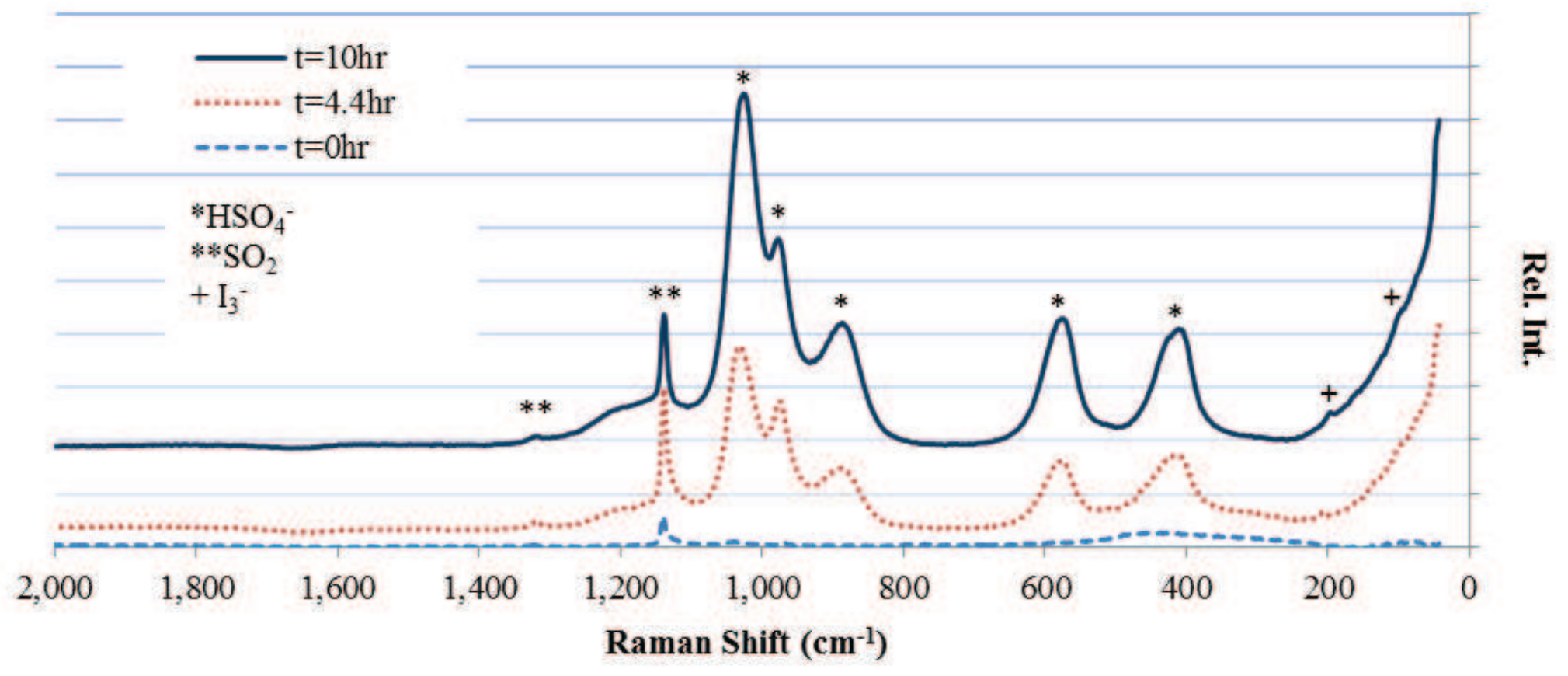

Fig. 9 

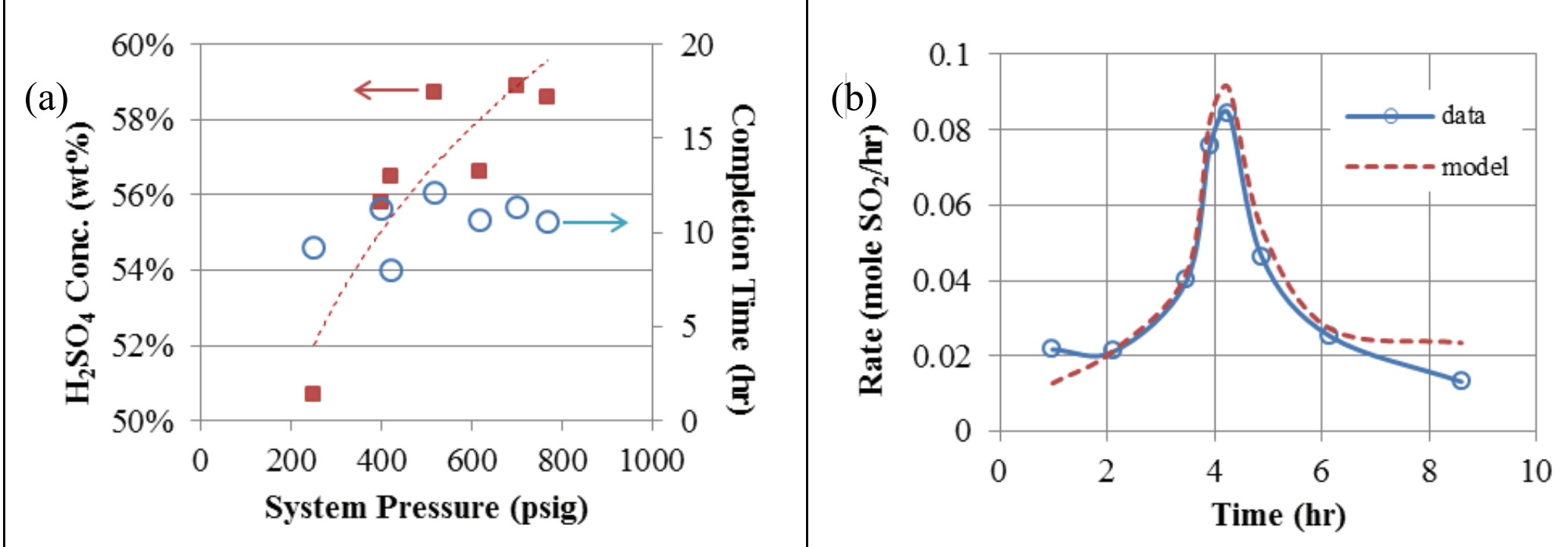

Fig. 10 
(a)

Fig. 11 


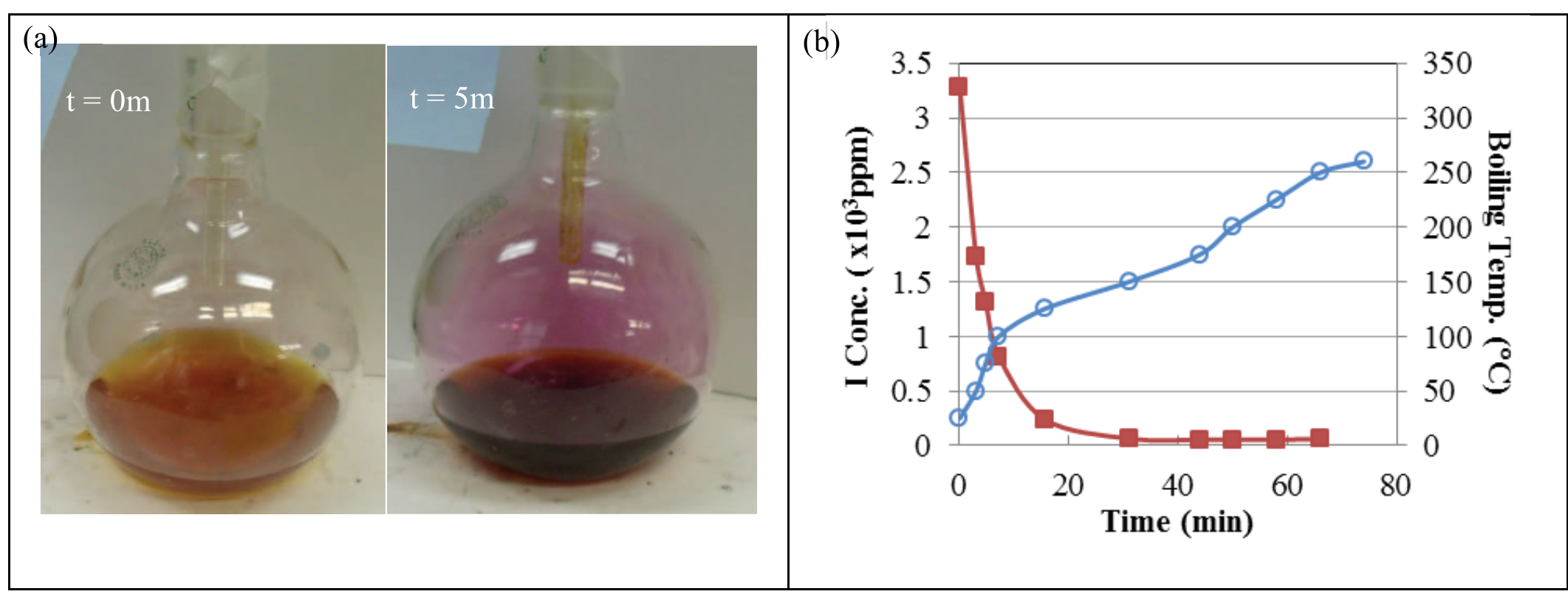

Fig. 12 


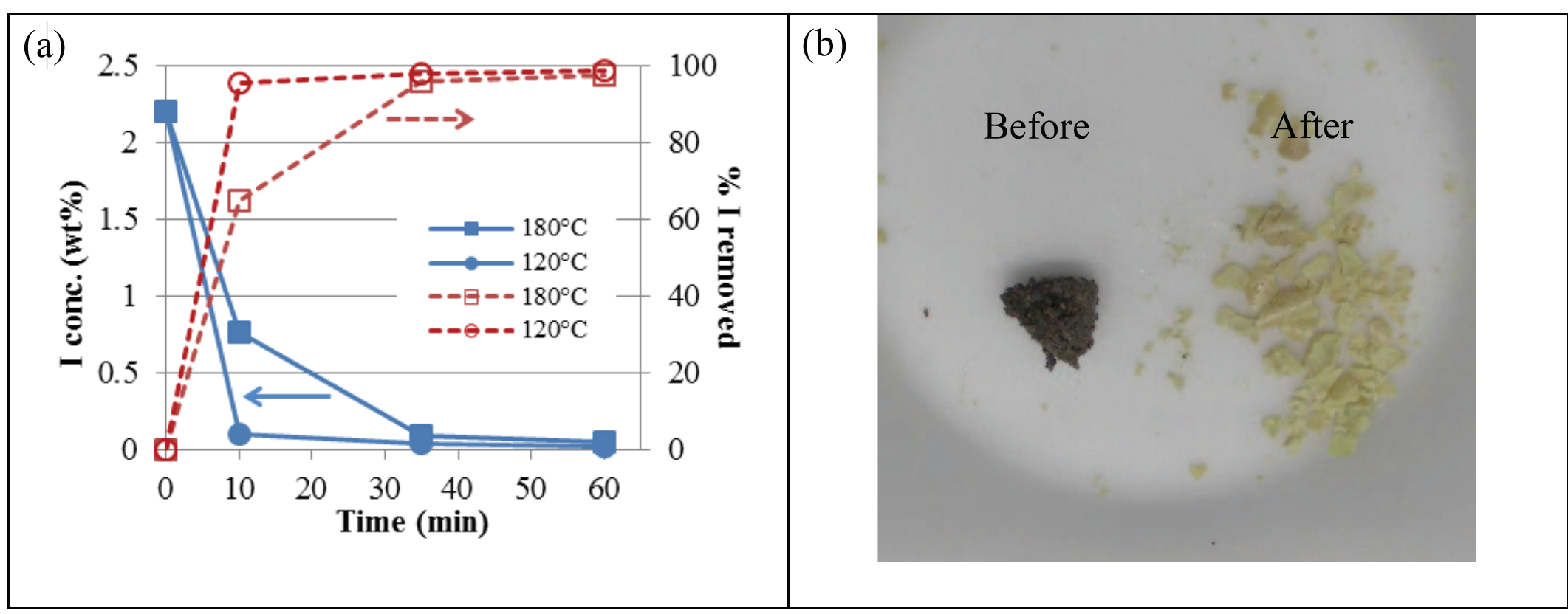

Fig. 13 
Figure 14

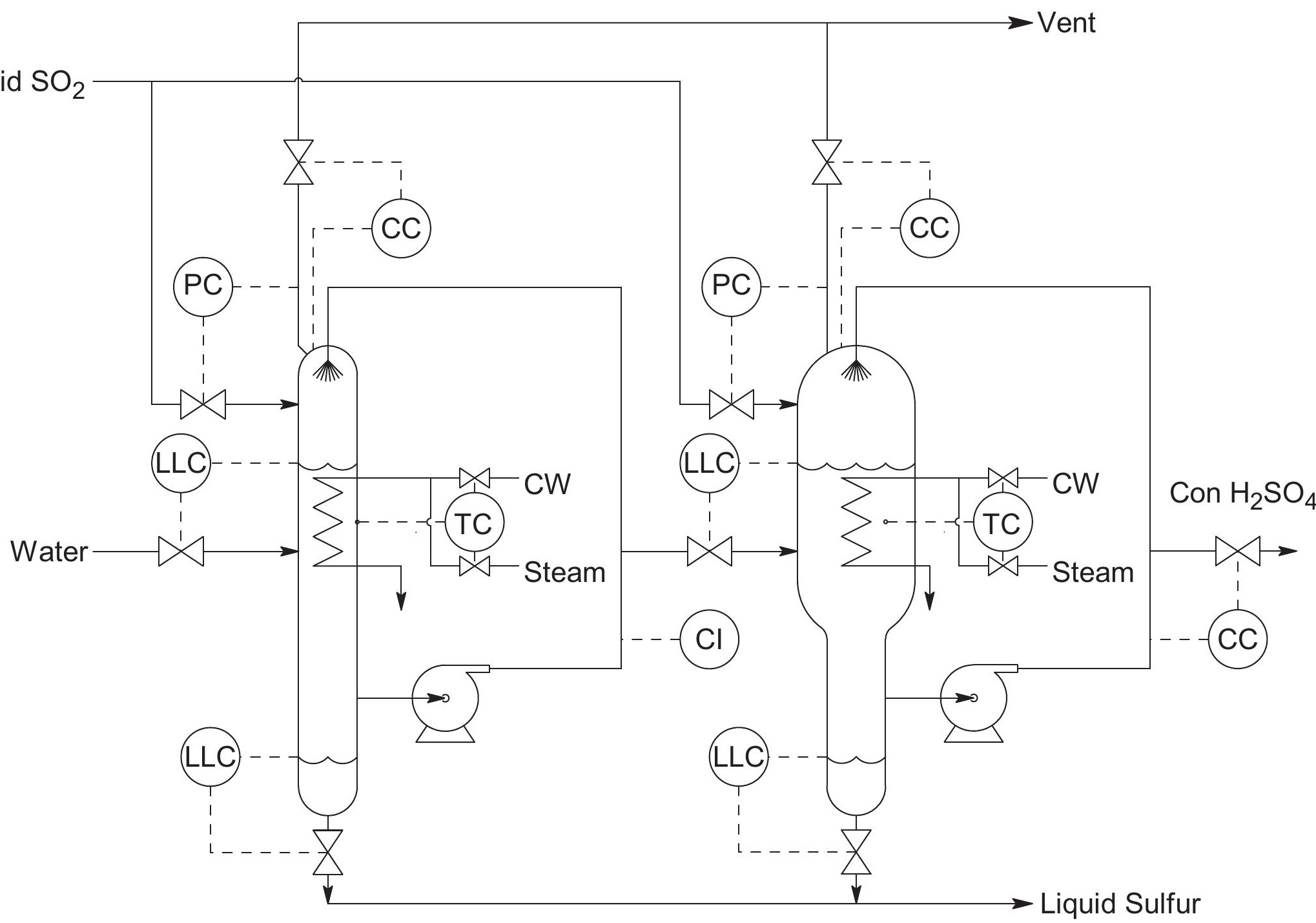

